\title{
A Beam Sweeping System for the Fermilab Antiproton Production Target
}

\author{
F.M. Bieniosek \\ Fermi National Accelerator Laboratory \\ P.O. Box 500, Batavia, Illinois 60510
}

August 1993 


\section{Disclaimer}

This report was prepared as an account of work sponsored by an agency of the United States Government. Neither the United States Government nor any agency thereof, nor any of their employees, makes any warranty, express or implied, or assumes any legal liability or responsibility for the accuracy, completeness, or usefulness of any information, apparatus, product, or process disclosed, or represents that its use would not infringe privately owned rights. Reference herein to any specific commercial product, process, or service by trade name, trademark, manufacturer, or otherwise, does not necessarily constitute or imply its endorsement, recommendation, or favoring by the United States Government or any agency thereof. The views and opinions of authors expressed herein do not necessarily state or reflect those of the United States Government or any agency thereof. 


\title{
A Beam Sweeping System for the Fermilab Antiproton Production Target
}

\author{
F. M. Bieniosek \\ Fermi National Accelerator Laboratory \\ Batavia, IL 60510
}

TM-1857

August 1993

\begin{abstract}
In the Main Injector era beam intensities high enough to damage the antiproton production target will be available. In order to continue to operate with a tightly-focused primary beam spot on the target, and thus maintain yield, it will be necessary to spread the hot spot on the target by use of a beam sweeping system. This report summarizes the requirements for such a system, and addresses the issues involved in the design of a sweeping system.
\end{abstract}

\section{Introduction.}

The efficiency of collecting antiprotons from the target rises as the size of the proton beam spot on the target is reduced. However the peak energy deposition on target rises even more rapidly. Under Main Injector conditions ( $5 \times 10^{12}$ protons in a $1.6-\mu$ s pulse), the spot size will have to be increased to at least $0.3 \mathrm{~mm}$ to keep peak energy deposition near current levels. The best available data ${ }^{1}$ on the dependence of yield on spot size indicates that an improvement of more than $20 \%$ in yield is obtained as the spot size is reduced from $0.3 \mathrm{~mm}$ to $0.1 \mathrm{~mm}$. To bring the density of energy deposition with a $0.1-\mathrm{mm}$ spot size back down to currently-existing levels, a system to sweep the beam spot on the target has been proposed.

Section II describes the physics issues involved in the sweeping system. A review of recent calculations and experimental work on the target indicates that no candidate target material is likely to be capable of withstanding the predicted energy densities. Requirements on a sweeping system imposed by the limitations of target materials and by the optics of the target station are described. The extreme conditions encountered downstream of the target, which impose unusual requirements on the design of the downstream magnets, are described. 
Section III discusses the design of magnets that are capable of meeting the requirements imposed in Section II. The downstream magnet is unusual in that the ferrite core is kept at the largest practical radius to minimize the heating by the shower of particles downstream of the target.

Section IV develops the design of a pulser circuit located on the floor of the AP() building that can drive the sweep magnets at the bottom of the target vault. Two designs are carried out: first, a circuit that drives the cables and sweep magnet in series; second a tuned circuit that couples the energy from a primary circuit at the pulser to a secondary circuit at the sweep magnet. The tuned circuit allows the step-up of current from the primary to the secondary circuits without at transformer, and efficient energy transfer in the presence of weak coupling between the two tuned circuits. Both of these features are directly applicable to the sweeping system. Somewhat better performance with a more modest pulser is obtained with the tuned circuit.

\section{Target Station Physics.}

\section{Limitations of target materials.}

Two major single-pulse target interaction problems have been identified. The first problem, transient shock wave effects, may induce void formation and fracturing in the material, as has been observed in heavy-metal targets. ${ }^{1}$ Early observations of mechanical damage in heavy-metal targets led to the decision during the 1989 collider run to change the target material to copper, despite a $10 \%$ drop in yield, because of its better thermoelastic properties. The second problem, localized melting of target material, leads to density depletion and consequent reduction in yield. Recent experimental results ${ }^{2}$ have confirmed our basic understanding of this second process, and indicate that we are approaching the physical limits of target materials. In addition, release of airborne radionuclides by molten target material has been observed, pointing out a potential safety problem when target material is melted by high-intensity beams.

Although the yield from proton-nucleon inelastic scattering scales approximately as $\sigma_{\text {abs }} \sim \mathrm{A}^{2 / 3}$ [Ref. 3], heavy metals are at a disadvantage in intense beam operations. This fact is summarized in Figures 1 and 2, which show quantities relevant to target performance for selected metallic elements.

Figure 1 shows a simple estimate of the energy required to melt candidate target materials, based on the approximation

$$
E_{m} \cong c_{p} T+Q_{f}
$$

where $\mathrm{E}_{\mathrm{m}}$ is the approximate melting point energy, $\mathrm{T}$ is the temperature in Celsius, $\mathrm{c}_{\mathrm{p}}$ is the room temperature specific heat, and $Q_{f}$ is the heat of fusion. Generally lighter metals have higher melting point energies. Because of reduced penetration lengths in heavier metals, energy deposition for a given beam intensity in heavy-metal target materials is greater than in lighter metals, ${ }^{4}$ increasing the relative advantages of the lighter metals such as copper and nickel.

The energy from the beam is deposited on a time scale of the beam pulse $(1.6 \mu \mathrm{s})$, much shorter than the time scale of thermal conduction of heat away from the beam $(\sim 100 \mu \mathrm{s})$. Therefore a channel of hot metal is created in the material, with local overpressure $\Delta \mathrm{P}$ related to the energy deposition $\Delta \mathrm{P}$ by the Mie-Grüneisen equation of state

$$
\Delta \mathrm{P}=\rho \gamma \Delta \mathrm{E}
$$


where $\gamma$ is the Grüneisen parameter. Some of the energy is carried away in a shock wave which may itself damage the target material; the remainder must be contained by the elastic properties of the target material until it is released by thermal conduction. The mechanical energy $\mathrm{W}$ imparted to the system may be estimated from the work of expansion of the hot channel against the surrounding material ${ }^{5}$

$$
\mathrm{W}=\int \mathrm{PdV} \cong\left(\frac{\gamma^{2} \rho^{2}}{2 \mathrm{~B}_{\mathrm{T}}}\right) \Delta \mathrm{E}^{2}
$$

where $\mathrm{B}_{\mathrm{T}}$ is the bulk modulus of the target material. This is the energy available to do mechanical damage to the target material. The factor $\gamma^{2} \rho^{2} / 2 \mathrm{~B}_{\mathrm{T}}$ is plotted in Figure 2 for some metals for which data are available. The strong shocks suggested by this formula for the heavy metals are consistent with the observed mechanical damage to these targets.

Copper and nickel both have relatively high melting point energies, and a low fraction of the energy appears as mechanical motion. Metals lighter than nickel are not at this time considered to be suitable target materials; in particular the expected yield drops rapidly for elements lighter than cobalt. Therefore it is unlikely that any suitable target material will be found in the future that can withstand much higher intensity beams than $\mathrm{Cu}$ and $\mathrm{Ni}$.

The copper target has operated at energy densities possibly as high as $600 \mathrm{~J} / \mathrm{g}$, near the melting point of copper, without mechanical damage. The target material was changed to nickel in the 1992-93 collider run. Figure 3 shows a comparison of the temperature of copper, nickel, and tungsten targets as a function of energy deposition. The solid curves indicate the temperature of copper and nickel, where corrections have been made for variations in specific heat at constant volume $c_{v}$ in the solid state as a function of temperature. The dotted lines indicate the solidliquid interface for the two metals. The slopes of the interface lines were calculated from generally-available data by using the Clausius-Clapeyron equation. Also shown for comparison is the curve for tungsten (W). Tungsten melts at temperatures above $3000 \mathrm{~K}$, although experience has shown that tungsten targets fracture at much lower energy densities (about 200 $\mathrm{J} / \mathrm{g}$ ). Note that copper approaches the solid-liquid interface in the $600 \mathrm{~J} / \mathrm{g}$ range, whereas nickel does not melt until the energy deposition is greater than $1000 \mathrm{~J} / \mathrm{g}$. In addition, the energy of mechanical motion (Figure 2) is lower in nickel than in copper for a given beam energy deposition. Therefore nickel may have somewhat more favorable properties than copper as a target material.

Figure $4^{6}$, based on results from the Monte-Carlo code MARS10, predicts that, in the absence of beam sweep, the energy density in copper for a spot size $\sigma_{x}=\sigma_{y}=0.1 \mathrm{~mm}$ will be $2800 \mathrm{~J} / \mathrm{g}$ at 5 $\mathrm{x} 10^{12}$ protons per pulse. The survey of candidate target materials above indicates that no target material is likely to survive under these conditions. Operation at this intensity requires a beam sweeping system. A sweep radius in the range of $0.25-0.33 \mathrm{~mm}$ reduces the peak energy deposition to below the melting point of copper, about $600 \mathrm{~J} / \mathrm{g}$. Nickel may withstand higher energy densities, allowing a smaller sweep radius. On the other hand, it would be difficult to build a sweeping system that reduces the energy deposition to levels compatible with heavy metal targets. Reducing energy density to less than $200 \mathrm{~J} / \mathrm{g}$ under Main Injector conditions would require a very large sweep radius (greater than $1 \mathrm{~mm}$ ). A sweep of this extent probably cannot be achieved. 
Table 1

Sweep Magnet Requirements

\begin{tabular}{lcc}
\hline & upstream & downstream \\
deflection: case (a) & $0.076 \mathrm{mrad}=0.31 \mathrm{kG}-\mathrm{m}$ & $0.95 \mathrm{mrad}=0.28 \mathrm{kG}-\mathrm{m}$ \\
deflection: case (b) & $0.18 \mathrm{mrad}=0.73 \mathrm{kG}-\mathrm{m}$ & $1.48 \mathrm{mrad}=0.44 \mathrm{kG}-\mathrm{m}$ \\
physical length & $35 \mathrm{~cm}$ & $30 \mathrm{~cm}$ \\
effective length & $28 \mathrm{~cm}$ & $22 \mathrm{~cm}$ \\
$\mathrm{~B}_{0}$ & $1.1-2.6 \mathrm{kG}$ & $1.3-2.0 \mathrm{kG}$ \\
\hline
\end{tabular}

2. Target station optics.

The standard beam sweeping scheme utilizes two upstream sweep magnets driven in quadrature to draw a circular pattern on the target with the $120-\mathrm{GeV}$ proton beam, followed by two downstream magnets to redirect the $8-\mathrm{GeV}$ antiprotons exiting the collection lens parallel to the AP2 transport line. ${ }^{7.8}$ Figure 5 shows a layout of the target station with sweeping system installed. The layout assumes a $35-\mathrm{cm}$ envelope upstream $(30-\mathrm{cm}$ downstream) for each sweep magnet. Sufficient space exists to locate the upstream sweep magnets at the end of the AP1 line, between magnet PQ9B and the toroid M:TOR109, near the focal point of the proton lens. The downstream magnets will be located at two currently unoccupied modules between the collection lens and the pulsed magnet. The deflection angles required at the upstream and downstream sweep magnets are shown in figures 6 and 7 as a function of the associated lithium lens field. Figure 8 shows the residual displacement after the downstream sweep magnets. Magnetic ficld strength requirements are listed in Table 1 for the modest case (a): no proton lens, collection lens at $800 \mathrm{~T} / \mathrm{m}$, and a sweep radius of $0.25 \mathrm{~mm}$, and the more ambitious case (b): proton lens at 2700 $\mathrm{T} / \mathrm{m}$, collection lens at $1000 \mathrm{~T} / \mathrm{m}$, and a sweep radius of $0.33 \mathrm{~mm}$. Case (b) represents expected future conditions and is taken as the nominal operating point in the remainder of this report. Requirements on the peak central field $B_{0}$ for case (b) are $2.6 \mathrm{kG}$ upstream, and $2.0 \mathrm{kG}$ downstream.

The residual downstream displacement is an unfortunate result of the fact that the downstream sweep magnets cannot be placed precisely on the focal point of the lithium lens. Thus it is not possible to simultaneously null out both the angular deflection and the position of the centroid of the beam. The displacement indicated in Fig. 8 remains after the angular deflection is removed by the sweep magnets, and effectively reduces the aperture of the AP2 transport line. Figure 9 shows a TURTLE calculation of a number of particles transported by the AP2 line into the Debuncher as a function of initial transverse beam displacement downstream of the collection lens. If the transverse displacement at the downstream sweep magnets is held below $1 \mathrm{~mm}$, very little deleterious effect on transmission efficiency is expected.

System requirements on timing jitter, field regulation, and field uniformity may be determined from the effective $\mathrm{RMS}$ radius $\mathrm{x}_{\mathrm{RMS}}$ of a displaced beam spot at the target

$$
\mathrm{x}_{\mathrm{RMS}}=\left(\sigma_{\mathrm{x}}^{2}+\Delta \mathrm{x}^{2}\right)^{1 / 2}
$$


where $\sigma_{x}$ and $\Delta \mathbf{x}$ are the Gaussian spot size and the displacement in a given direction. If we wish to limit the increase in $\mathrm{x}_{\mathrm{RMS}}$ to less than $10 \%$ in all cases, the basic criterion becomes $\Delta \mathrm{x} / \sigma_{\mathrm{x}}<0.46$, or, typically, $\Delta \mathrm{x}<0.05 \mathrm{~mm}$.

Timing jitter/sweep time. Timing jitter between horizontal-vertical magnet pairs causes a deviation of the beam path from a perfect circle. Timing jitter between upstream-downstream magnet pairs causes a lag or lead of the kicker partners with respect to each other as they trace out circular paths. By examining the distortions created by these errors, one may determine that the $10 \%$ criterion above leads to a combined timing jitter requirement $\Delta \mathrm{t}_{\mathrm{j}}< \pm 30 \mathrm{~ns}$. In addition, the magnet sweep periods are also restricted to agree to within $\pm 30 \mathrm{~ns}$, out of $1.6 \mu \mathrm{s}$.

Field uniformity/regulation. If we again limit the distance the upstream and downstream paths are allowed to be displaced with respect to each other, the requirement becomes $\Delta \mathrm{B} / \mathrm{B}_{0}< \pm 7 \%$ : for both field uniformity and pulse-to-pulse field regulation in the sweep magnets.

\section{Target environment.}

MARS 10 and CASIM calculations of energy deposition by hadron and electromagnetic cascades show significant heating of iron and ferrite magnet cores downstream of the target. ${ }^{9}$ The total heating increases linearly with particle flux, and is a strong function of the radius of the magnet core. Steady-state temperature rise of the core is determined by thermal conductivity of the material and the rate at which heat is removed at the surface. There is some concern that magnets built using ferromagnetic materials will fail to operate under Main Injector conditions if the steady-state temperature exceeds the Curie temperature of the material. This is especially true in the case of ferrite material, in which both the Curie temperature (typically ahout 200 C) and the thermal conductivity are low. Design of the downstream sweep magnet must address this concern by minimizing the utilization of magnetic material at small radii, where the energy deposition is greatest.

Ionization of the air by the particle shower will increase the conductivity of the air between the conductor plates. Electrical losses through the ionized-air path across the gap reduce the Q of the circuit driving the magnet. In order to quantify this effect, CASIM was used to determine the energy deposition in the air downstream of the target and the lithium lens. Results showed that with $5 \times 10^{12}$ protons per pulse on target, the energy deposition in the air $40 \mathrm{~cm}$ downstream of the target at a radius of $1.5 \mathrm{~cm}$ is about $1.5 \mathrm{~J} / \mathrm{g}$. Electron density $\mathrm{n}_{\mathrm{e}}$ in the air as a function of time is then estimated by the equation

$$
\frac{d n_{e}}{d t}=\frac{1}{e W_{i}}\left(\frac{d E}{d t}\right)+v_{a v} n_{e}-\alpha n_{e}^{2}
$$

where $\mathrm{eW}_{\mathrm{i}}$ is the mean energy required to produce an electron-ion pair (about $\left.33 \mathrm{eV}\right),(\mathrm{dE} / \mathrm{d} \mathrm{t}$ ) is the rate of energy deposition (from CASIM), $v_{a v}$ is the avalanche ionization coefficient (a function of the ratio of electric field to gas pressure $E / p$ ), and $\alpha$ is the recombination coefficien1 (about $2.2 \times 10^{-6} \mathrm{~cm}^{3} / \mathrm{sec}$ in air $^{10}$ ). The simplest model of low-frequency plasma conductivity gives the expression

$$
\sigma=\frac{\mathrm{n}_{\mathrm{e}} \mathrm{e}^{2}}{\mathrm{~m}_{\mathrm{e}} v_{\mathrm{m}}}
$$


where e and $\mathrm{m}_{\mathrm{e}}$ are electron charge and mass. The momentum-transfer collision frequency for electron-neutral collisions, $v_{m}$, is in turn given by

$$
v_{m}=\frac{e}{m_{e}} \frac{E}{V_{d}}
$$

where the electron drift velocity $V_{d}$ in air is ${ }^{10}$

$$
V_{d} \cong 7.0 \times 10^{5}+5 \times 10^{5}\left(\frac{E}{p}\right) \mathrm{cm} / \mathrm{sec} .
$$

Typical E/p in this case is on the order of $1 \mathrm{~V} / \mathrm{cm} / \mathrm{Torr}$; at this field avalanche ionization should be small, and is neglected. Solving Equation (5) for $\mathrm{dn}_{\mathrm{e}} / \mathrm{dt}=0$, the equilibrium electron density during the beam pulse is $\mathrm{n}_{\mathrm{e}}=1 \times 10^{13} \mathrm{~cm}^{-3}$. Equation (6) then yields the conductivity of the air $\sigma=0.25 \mathrm{siemen} / \mathrm{m}$. The conductivity rises to this level at the beginning of the beam pulse, then decays away after the end of the pulse. The resistance $R$ across a pair of plates of length $l=30 \mathrm{~cm}$, gap $a=3 \mathrm{~cm}$, and width $b=3 \mathrm{~cm}$ is given by the expression

$$
\mathrm{R}=\frac{4 a}{\sigma l b}
$$

where the 4 comes from the fact that the average voltage across the plates is about $1 / 4$ of the full voltage. In this case $\mathrm{R} \approx 50 \Omega$. A leakage resistance of this size is within an order of magnitude of seriously affecting the operation of the sweep magnets, and is included in the circuit model below. Avalanche breakdown of the air does not appear to be a problem, as long peak electric fields are kept well below breakdown levels, i.e. $\mathrm{E}<10 \mathrm{kV} / \mathrm{cm}$.

Finally, the intense radiation level will destroy most organic insulating materials. Hence, voltage drops across the magnet, and reliance on solid insulation, should be kept to a minimum.

\section{Sweep Magnets.}

\section{Downstream magnets.}

The most challenging design problems are posed by the downstream sweep magnets. Threc distinct approaches have been studied in the past. They all have problems which make their implementation unappealing. 11

Ferrite core. Magnets designed with a ferrite core have the problem of heating of the ferrite by beam energy deposition downstream of the target. The temperature builds up to high levels because of poor thermal conductivity, and field regulation becomes unacceptable duc to the dependence of $\mu$ on the temperature of the ferrite. In many cases the ferrite is heated beyond its Curie temperature.

Laminated steel core. The thermal conductivity of a laminated steel core is much higher than that of a ferrite core. Thus it is easier to remove the heat buildup in the core. Unfortunately very thin laminations 0.001 " thick are required at the frequency of operation. This necessity leads to concerns with the dielectric strength of the insulation between laminations in the high radiation environment in the target vault. 
Air core. An air core magnet has no heat buildup problem. However stray fields, eddy cuirents in metal walls, etc., force operation with much larger currents than would otherwise he necessary, and distort the field profile in the magnet gap. ${ }^{12}$

The approach taken in this report is a hybrid air/ferrite-core sweep magnet. The two currentcarrying plates are roughly $3-\mathrm{cm}$ wide, with a $3-\mathrm{cm}$ air gap. A ferrite toroid surrounding the plates provides a return path for the magnetic field. This design appears to have several advantages:

1. The ferrite remains at a large radius, thereby reducing heating by the shower of particles downstream of the target.

2. Peak electric fields between the current-carrying conductors and the ferrite may be kept below the breakdown threshold for air, allowing the design of a magnet with a minimal amount of solid insulation.

3. The dependence of magnetic field strength on $\mu$ of the ferrite is weaker than in designs in which ferrite pole pieces are placed near the beam. Thus it is likely that the ferrite can be safely operated to higher temperature.

4. The symmetric shape of the ferrite toroid may reduce the danger of stress fracturing of the brittle ferrite material during repetitive pulsed heating.

A preliminary study of the properties of such a magnet was carried out, using the program POISSON. Some shaping of the conductors was performed in an attempt to minimize the current required for a given magnetic field, while maintaining field uniformity inside a circle of radius $1.1 \mathrm{~cm}$. The resulting shapes for the conductor and the ferrite toroid are plotted in Figure 10 , together with the magnetic field lines, for an inner ferrite radius of $3 \mathrm{~cm}$. The horizontal and vertical axes in the plot are the axes of symmetry. The current required to deliver a central field of $2 \mathrm{kG}$ is $7870 \mathrm{~A}$; the inductance per unit length calculated from the stored energy is $0.7135 \mu \mathrm{H} / \mathrm{m}$. Figure 11 shows how the current requirement varies with inner radius of the ferrite toroid (plotted is half of the total current); figure 13 shows the dependence of required current on the $\mu$ of the ferrite. Magnet performance depends rather strongly on toroid radius, but the magnet is insensitive to variations in $\mu$ for $\mu>100$. Similar results for the effects on the quadrupole and sextupole terms in the magnetic field at the $1.1-\mathrm{cm}$ radius circle are plotted in Figs. 12 and 14. These plots show that the presence of the ferrite tends to reduce higher-order field terms. Transverse electric fields peak near the tips of the conductors at about $5 \mathrm{kV} / \mathrm{cm}$. The final radius chosen for the toroid will depend on the results of ANSYS thermal stress calculations for the beam-heating model, and for specific ferrite materials.

A side view of the downstream sweep magnet is shown in Fig. 16. In the center-fed design (a) the electric field is small across the bore of the magnet; the largest field is at the current leads. A balanced center-fed design (b), in which a pair of current leads is placed at both the top and bottom conductors, provides greater symmetry and reduces the field at the current leads. But the inductance of the magnet is probably too small to drive efficiently. A full 3-D calculation of the magnetic fields, including end effects and current leads, remains to be done.

\section{Upstream magnets.}

The upstream sweep magnets can be more conventional. A design is shown in Fig. 17. The conductors are $2.2 \mathrm{~cm} \times 2.2 \mathrm{~cm}$ (size $\times$ gap), and the ferrite core is of "picture frame" design. Space is provided between the conductors and the core for electrical insulation. The quadrupole and sextupole field components on a $1-\mathrm{cm}$ radius circle are $1.8 \%$ and $0.9 \%$ respectively. An effective aperture of $1-\mathrm{cm}$ radius should be adequate, since the $95 \%$ beam size is about $2 \mathrm{~mm}$ at this location. Current required for a central field of $2.6 \mathrm{kG}$ is $5024 \mathrm{~A}$, and the inductance is 1.13 $\mu \mathrm{H} / \mathrm{m}$. This magnet will be longer than the downstream magnet, so end effects should be less of a problem. Care should be taken to avoid saturation of the ferrite in the high-field corners of the 
core. An evacuated beam pipe is not necessary at this location, since the scattering of a $120-\mathrm{GeV}$ proton beam through an additional $70 \mathrm{~cm}$ of air is negligible.

\section{Pulser Circuit.}

The sweep magnets must be provided with a high-current $625-\mathrm{kHz}$ sine wave by a power supply located on the floor of the AP0 service building. The current will be supplied over a distance of approximately $9 \mathrm{~m}$ by multiple parallel lines of coaxial cable (RG-220) into the target vault, and through $2.5 \mathrm{~m}$ of strip line to the magnet at the bottom of the module. Difficulties in supplying large currents to the sweep magnets through long cables are expected. The inductance of the cables, in series with the sweep magnets, significantly increases the requirements on the power supply.

An improvement on the series circuit that avoids this problem is based on the simple dualresonant circuit, shown in Figure 18 (a). This circuit ${ }^{13,14}$ is commonly used for pulse-charging high voltage equipment, and for Tesla coils. At resonance, the natural frequencies of the primary and secondary circuits of the transformer are equal: $L_{1} C_{1}=L_{2} C_{2}$, where $C_{1}$ is the primary circuit capacitor charged to an initial voltage $\mathrm{v}_{10}, \mathrm{C}_{2}$ is the capacitance of the secondary circuit, and $\mathrm{L}_{1}$ and $\mathrm{L}_{2}$ are the inductances of the primary and secondary circuits, respectively. A pulse transformer allows step-up to arbitrary voltages in the secondary circuit. For certain values of coupling between the primary and secondary circuits, all the energy initially stored in capacitor $\mathrm{C}_{1}$ may be transferred to capacitor $\mathrm{C}_{2}$. The number of voltage reversals $n$ required to completely transfer the energy from the primary circuit to the secondary circuit depends on the magnetic coupling coefficient $\mathrm{k}_{\mathrm{m}}$. If the circuit is in resonance, at time $t$ after the switch is closed the voltages of the primary and secondary circuits are

$$
\begin{aligned}
& v_{1}=v_{10}\left(\cos n \omega_{0} t+\cos m \omega_{0} t\right) \\
& v_{2}=v_{10}\left(\frac{C_{1}}{C_{2}}\right)^{1 / 2}\left(\cos n \omega_{0} t-\cos m \omega_{0} t\right)
\end{aligned}
$$

where $\mathrm{n}$ and $\mathrm{m}$ are whole numbers. The resonant modes of interest to this application are $\mathrm{n}=$ $1,2,3, \ldots$ and $m=n+1$. The conditions on circuit parameters are

$$
\begin{aligned}
& \omega_{0}^{2} L C=\left(\frac{m^{2}+n^{2}}{2 n^{2} m^{2}}\right) \\
& k_{m}^{2}=\left(\frac{m^{2}-n^{2}}{m^{2}+n^{2}}\right) .
\end{aligned}
$$

The expressions for the voltage may be rewritten as the product of two sine waves at the frerquencies $(m+n) \omega_{0}$ and $(m-n) \omega_{0}$. The frequency of the fast oscillation is slightly higher than the resonant frequency of the individual uncoupled circuits, and is the oscillation useful for a fast beam sweep system. The frequency of the slow oscillation is strongly dependent on the coupling coefficient $\mathrm{k}_{\mathrm{m}}$, and represents the rate at which energy is transferred between the coupled oscillators. 
The circuit of Fig. 18(b) is a special case of that shown in Fig. 18(a). The circuit components now correspond to the parts of the sweeping system as follows: $C_{1}$ is the energy-storage capacitor, $\dot{L}_{1}$ is the inductance of the pulser and cable, $C_{2}$ is the secondary capacitor, and $L_{2}^{\prime}$ is the inductance of the sweep magnet. This circuit resonantly transfers energy from the primary loop to the secondary loop if the following conditions (which replace Eq. 12) are satisfied:

$$
\begin{aligned}
& \omega_{0}^{2} \mathrm{~L}_{1} \mathrm{C}_{1}=\left(\frac{2}{\mathrm{n}^{2}+\mathrm{m}^{2}}\right) \\
& \omega_{0}^{2} \mathrm{~L}_{2} \mathrm{C}_{2}=\left(\frac{\mathrm{m}^{2}+\mathrm{n}^{2}}{2 \mathrm{n}^{2} \mathrm{~m}^{2}}\right)
\end{aligned}
$$

The voltage gain of the circuit, $V_{g}$, is determined by the resonant mode chosen, and it in turn determines the ratio of the two capacitors:

$$
\mathrm{V}_{\mathrm{g}}=\left(\frac{\mathrm{C}_{1}}{\mathrm{C}_{2}}\right)^{1 / 2}=\left(\frac{\mathrm{m}^{2}-\mathrm{n}^{2}}{\mathrm{~m}^{2}+\mathrm{n}^{2}}\right)
$$

The mode chosen for detailed study is $n=2, m=3$. The primary circuit voltage and secondary circuit current waveforms for an ideal resonant circuit of this type are shown in Fig. 19. The lossless voltage gain is 0.385 , implying a current step-up of about 2.6. With higher-order modes there is less direct coupling to the load, but the voltages at the primary circuit become higher, additional unnecessary voltage reversals appear on circuit components, and the circuit requires a higher $\mathrm{Q}$ to operate efficiently.

Fig. 20 shows the model used for SPICE calculations of the driving circuit. Component values are listed in Table 2. Calculations for two pairs of circuits have been performed: series circuits which supply current in series through the cable to the magnets, and dual-resonant circuits with secondary capacitors. The fire and dump switches are hydrogen thyratrons, modeled as ideal switches with a fixed series resistance and inductance. The cable consists of 16 parallel lines of RG-220, 9 meters in length (10 meters upstream). Resistances of cables are as indicated; additional reflection-damping resistors are included. A $2.5-\mathrm{m}$ long, $10-\mathrm{cm}$ wide stripline connects the secondary capacitor at the top of the target vault with the downstream sweep magnets at the bottom of the target vault. The upstream secondary capacitors are located directly at the sweep magnets. The shunt resistance, RPL, of the ionized air across the current conductors in the downstream magnet is (conservatively) represented by a fixed $10 \Omega$ resistor.

Figure 21 shows the waveform in the downstream series circuit. The dashed curve represents the voltage at the point V1 indicated in Fig. 20. The initial voltage is $32 \mathrm{kV}$, but the full voltage does not appear at V1 after turn-on because of the large inductive drop across the 'fire' switch thyratron. The value of energy storage capacitance $C_{1}$ was chosen to generate a damped sine wave at the magnet with a period of $1.6 \mu \mathrm{s}$. The output current waveform, plotted as twice the value of the current through the sweep magnet, I(sweep), is distorted, most strongly in the initial half-cycle, by reflections in the cable. As a result the sweep magnets do not trace out a circle on the target, and are difficult to match between upstream and downstream. In addition, the current that must be supplied by the pulser, I(fire), is large -- nearly identical to the current at the sweep magnet -- and the initial rate of rise of current in the switch is extremely high. Installation of a 2:1 pulse transformer in the target vault could allow a more efficient coupling of energy to the 
sweep magnets. Peak primary circuit current drops in this case to $5.2 \mathrm{kA}$. However the operating voltage increases (to $45 \mathrm{kV}$ ), and the cable reflections remain.

Table 2

Components of sweeping circuit models

\begin{tabular}{|c|c|c|c|c|c|}
\hline Name & Description & $\begin{array}{c}\text { Downstream } \\
\text { (series) }\end{array}$ & $\begin{array}{c}\text { Upstream } \\
\text { (series ) }\end{array}$ & Downstream & Upstream \\
\hline RSW1 & Fire switch resisitance & $0.02 \Omega$ & $0.02 \Omega$ & $0.02 \Omega$ & $0.02 \mathrm{~s} 2$ \\
\hline LSW 1 & Fire switch inductance & $0.2 \mu \mathrm{H}$ & $0.2 \mu \mathrm{H}$ & $0.2 \mu \mathrm{H}$ & $0.2 \mu \mathrm{H}$ \\
\hline RSW2 & Dump circuit resistance & - - - - & -....- & $10 \Omega$ & $10 \Omega$ \\
\hline LSW2 & Dump circuit inductance & $\ldots$ & $\cdots+-$ & $1.0 \mu \mathrm{H}$ & $1.0 \mu \mathrm{H}$ \\
\hline $\mathrm{C} 1$ & Energy storage capacitor & $0.07 \mu \mathrm{F}$ & $0.065 \mu \mathrm{F}$ & $0.035 \mu \mathrm{F}$ & $0.028 \mu \mathrm{F}$ \\
\hline L1 & Pulser circuit inductance & $0.2 \mu \mathrm{H}$ & $0.2 \mu \mathrm{H}$ & $1.4 \mu \mathrm{H}$ & $2.0 \mu \mathrm{H}$ \\
\hline R1 & Reflection-damping resistor & $50 \Omega$ & $25 \Omega$ & $100 \Omega$ & $100 \Omega$ \\
\hline RT1A & Half of cable resistance & $0.02 \Omega$ & $0.02 \Omega$ & $0.02 \Omega$ & $0.02 \Omega$ \\
\hline T1 & 16 RG-220 cables $(9 / 10-\mathrm{m})$ & $50 \mathrm{~ns} / 3.13 \Omega$ & $55 \mathrm{~ns} / 3.13 \Omega$ & $50 \mathrm{~ns} / 3.13 \Omega$ & $55 \mathrm{~ns} / 3.1 .3 \Omega$ \\
\hline RT1B & Half of cable resistance & $0.02 \Omega$ & $0.02 \Omega$ & $0.02 \Omega$ & $0.02 \Omega$ \\
\hline R2 & Reflection-damping resistor & $50 \Omega$ & $25 \Omega$ & $100 \Omega$ & $100 \Omega$ \\
\hline $\mathrm{C} 2$ & Secondary capacitor & ----- & ------ & $0.17 \mu \mathrm{F}$ & $0.17 \mu \mathrm{F}$ \\
\hline LC2 & Inductance of $\mathrm{C} 2$ & ----- & $--\cdot--$ & $0.02 \mu \mathrm{H}$ & $0.02 \mu \mathrm{H}$ \\
\hline RT2A & Half of strip-line resistance & $0.005 \Omega$ & $\cdots$ & $0.005 \Omega$ & .....- \\
\hline T2 & Strip line $(2.5-\mathrm{m})$ & $16 \mathrm{~ns} / 1.3 \Omega$ & ---- & $16 \mathrm{~ns} / 1.3 \Omega$ & $-\cdots$ \\
\hline RT2B & Half of strip-line resistance & $0.005 \Omega$ & ----- & $0.005 \Omega$ & ----- \\
\hline L2 & Inductance of sweeper & $0.3 \mu \mathrm{H}$ & $0.4 \mu \mathrm{H}$ & $0.3 \mu \mathrm{H}$ & $0.4 \mu \mathrm{H}$ \\
\hline $\mathrm{CL} 2$ & Capacitance of sweeper & $1.2 \mathrm{nF}$ & $1.2 \mathrm{nF}$ & $1.2 \mathrm{nF}$ & $1.2 \mathrm{nF}$ \\
\hline RPL & Resistive loss across plates & $10 \Omega$ & $\cdots$ & $10 \Omega$ & ..... \\
\hline
\end{tabular}

Figure 22 shows the waveforms in a tuned circuit based on the $n=2, m=3$ resonance. There are no noticeable distortions in the output current waveform. Peak current, rate of rise of current and current reversal in the primary circuit have all been significantly reduced. Similar behavior is observed in the upstream circuit, as shown in Fig. 23 for the series circuit, and in Fig. 24 for the tuned circuit.

The paths traced on the target by both pairs of sweep magnets operated in quadrature (offset in time by $0.4 \mu \mathrm{s}$ ) are shown for the series circuit in Figure 25 . The solid line represents the curve traced by the downstream sweep magnets, and the dashed line represents the curve traced by the upstream sweep magnets. The paths begin at the top of the figure, and proceeds in a clockwise spiral. The distortions in the waveforms are initially large, and they do not agree to within the desired tolerance of $0.05 \mathrm{~mm}$, until at least $1 / 4$ rotation is completed. Beginning the beam puls: at that time, and following the spiral path around one complete rotation, the average sweep radius is $0.33 \mathrm{~mm}$. The rates of resistive decay of the two circuits were matched by adjusting the values of the reflection-damping resistors so that the paths agree at later times.

Figure 26 shows the upstream and downstream paths traced with the tuned circuit. The paths make a partial small loop before and after making the large loop (motion is clockwise). The two paths agree to within the required tolerance and the average sweep radius is $0.33 \mathrm{~mm}$. The sweep system in one plane should be turned on approximately $1.3 \mu$ s before the beginning of the beam pulse; the other plane should be turned on $0.4 \mu$ s later $(0.9 \mu$ s before the beam). Motion of the beam spot in a nearly-circular pattern begins at the start of the beam pulse and returns to close the circle in $1.6 \mu \mathrm{s}$. The residual discrepancy between the two curves is due to the fact that 
the two circuits are not precisely at resonance, and that no effort was made to match the rates of resistive decay in the two circuits.

Table 3

Circuit currents and voltages

\begin{tabular}{lllll}
\hline Description & $\begin{array}{c}\text { Downstream } \\
\text { (series) }\end{array}$ & $\begin{array}{c}\text { Upstream } \\
\text { (series) }\end{array}$ & Downstream & Upstream \\
Initial charge voltage & $32 \mathrm{kV}$ & $23 \mathrm{kV}$ & $33 \mathrm{kV}$ & $22 \mathrm{kV}$ \\
Peak fire circuit current & $7 \mathrm{kA}$ & $5 \mathrm{kA}$ & $4.3 \mathrm{kA}$ & $2.2 \mathrm{kA}$ \\
Initial fire circuit dI/dt & $60 \mathrm{kA} / \mu \mathrm{s}$ & $50 \mathrm{kA} / \mu \mathrm{s}$ & $15 \mathrm{kA} / \mu \mathrm{s}$ & $7 \mathrm{kA} / \mu \mathrm{s}$ \\
Fire circuit current reversal & $90 \%$ & $80 \%$ & $65 \%$ & $65 \%$ \\
Peak magnet current & $8 \mathrm{kA}$ & $5 \mathrm{kA}$ & $8 \mathrm{kA}$ & $5 \mathrm{kA}$ \\
Peak dump circuit current & & & $1 \mathrm{kA}$ & $0.9 \mathrm{kA}$ \\
\hline
\end{tabular}

Current and voltage requirements of the circuits are summarized in Table 3 . The tuned-circuit approach appears to be superior, because its requirements on the equipment in the pulser are in a reasonable range. A switch tube that may be adequate to drive the tuned circuit is the EEV double-ended thyratron CX1174B. It is rated at $35 \mathrm{kV}, 6 \mathrm{kA}$, and because of its double-ended design it can conduct current in both directions. Timing jitter is less than 5 ns. A sturdier tuhe would be required to operate the series circuit.

As already mentioned, it will be necessary to carefully tune all four sweep circuits to match their sweep times to $1.6 \mu \mathrm{s}$. There is an additional requirement on the tuned circuit, that the primary and secondary loops be in reasonable tune with each other. However the tolerance on the agreement between primary and secondary tune is less strict than the tolerance on the overall sweep time. Hence tuning the primary and secondary loops with respect to each other is likely to be less difficult than tuning for the correct sweep times.

The ringing waveforms in the circuit naturally decay away on the time scale of many $\mu s$. In order to eliminate unnecessary voltage reversals on circuit components, it would be advantageous to dump the remaining energy into a resistor after the beam has passed. The hest time to do this is at the end of the beam pulse, when the circuit naturally transfers the energy back upstairs to the pulser. Firing a dump switch (labelled 'DUMP' on fig. 20) at $2.8 \mu$ s quickly damps out the ringing in the circuit (fig. 27). Care must be taken to prevent the dump switch tube from prefiring during the two voltage reversals between 0 and $2.8 \mu$ s. No dump circuit calculations were made for the series circuit.

I would like to thank K. Anderson, K. Fullett, J. Dinkel, and S. O'Day for helpful discussions on various aspects of this report.

1M. Gormley, memo, 8 Aug. 1988.

${ }^{2} \mathrm{~S}$. O'Day, F. Bieniosek, and K. Anderson, New target results from the FNAL Antiproton

Source, Proc. 1993 Particle Accelerator Conference. Pbar Notes \#512, \#532.

3 J. V. Allaby, CERN-84-15, p. 63, 20 Dec. 1984.

${ }^{4}$ I. L. Azhgirey, N. V. Mokhov, S. I. Striganov, Antiproton production for Tevatron, FermilabTM-1730 (1991).

5Z. Tang and K. Anderson, Shock waves in p-bar target, Fermilab-TM-1763 (Nov. 1991).

${ }^{6}$ C. M. Bhat and N. V. Mokhov, Calculation of beam sweeping effect for the Fermilah

Antiproton Source, Fermilab-TM-1585 (April 1989).

7 T. Vsevolzhskaya, G. Silvestrov, A. Chernyakin, J. Maclachlan, The proton beam sweeping system for an antiproton target station using lithium lenses, Fermilab-TM-1048 (June 1981). G. 
I. Silvestrov and A. D. Cherniakin ,A sweeping system for producing secondary beams with high phase density, IIF-Preprint-84-120 (1984). [translation LA-tr--86-24].

8 A slow one-dimensional linear sweep may avoid some of the complexity of the rapid circular sweeping system, but is impractical because the linear extent of sweep must be 2-3 times larger than the diameter of circular sweep; hence losses will occur due to the limited aperture of the proton lens and of the AP2 line.

${ }^{9}$ C. M. Bhat, Some design considerations for pbar target sweeping station, Fermilab-TM-1743 (June 1991).

10 S. C. Brown. Basic Data of Plasma Physics, J. Wiley, 1959.

11 C. Crawford, memo, 28 Feb. 1989.

12 A. Jason, et. al. IEEE Trans. Nucl. Sci. NS-30, 2938 (1983).

13D. Finkelstein, P. Goldberg, and J. Shuchatowicz, Rev. Sci. Instrum. 37, 159 (1966).

${ }^{14}$ E. A. Abramyan, Rev. Sci. instrum. 61, 1717 (1971). 


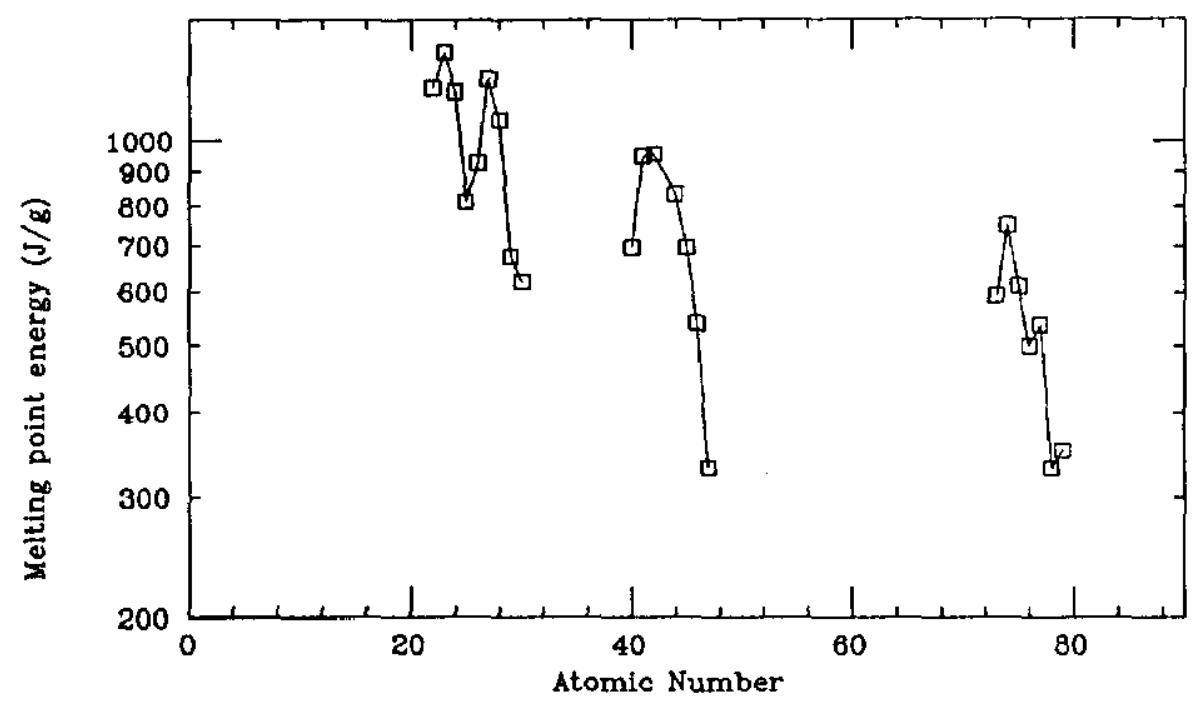

Fig 1. Energy required to melt target materials.

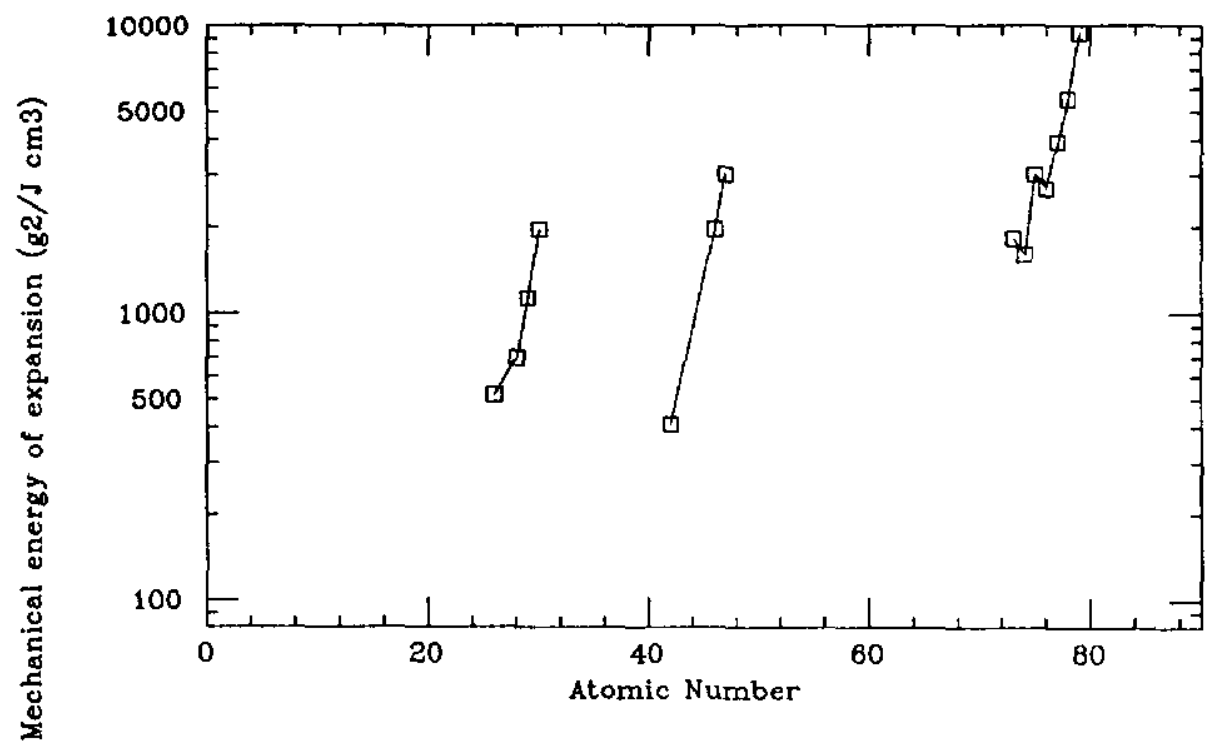

Fig 2. Energy of expansion for a fixed beam energy deposition. 


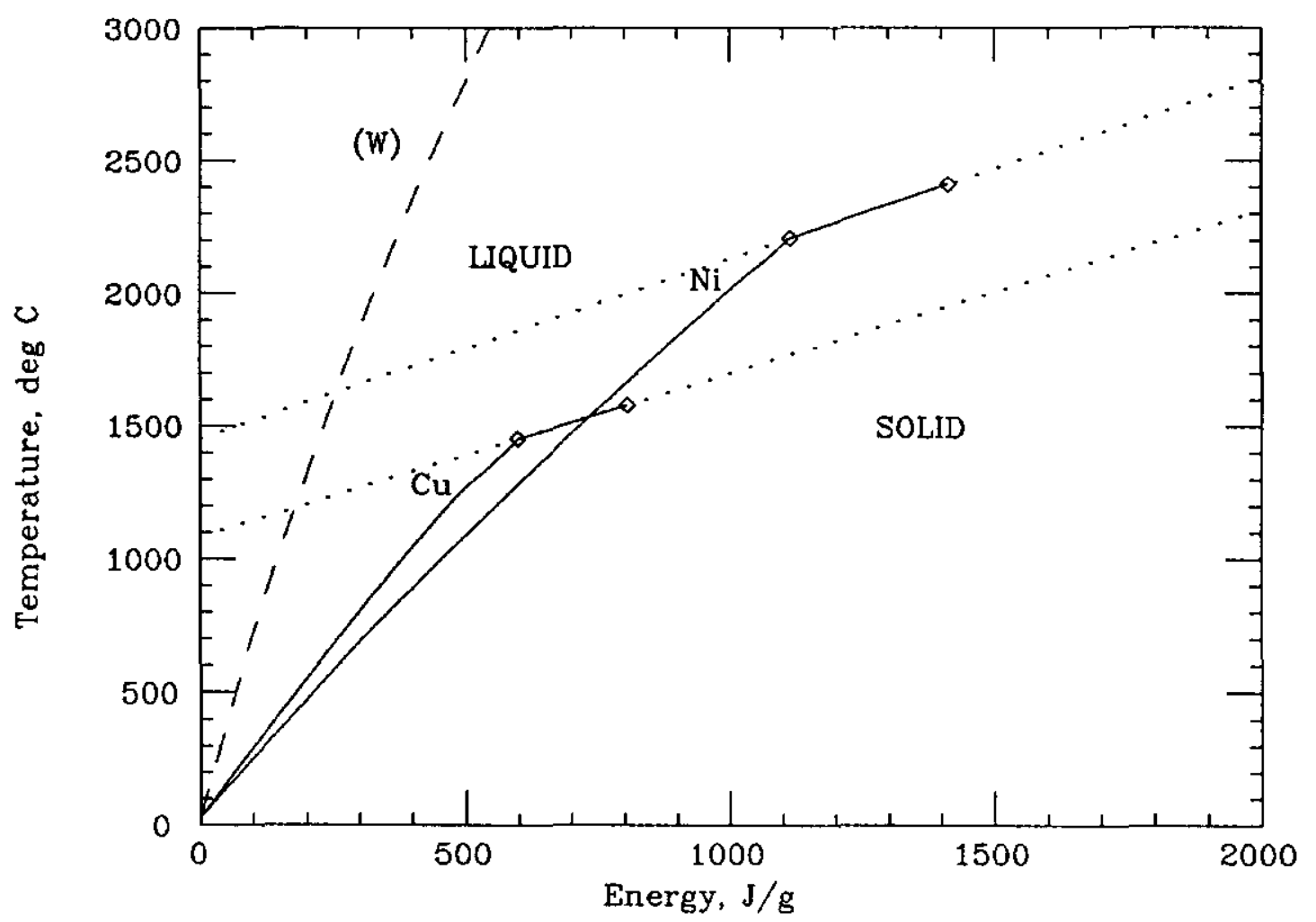

Fig.3. Temperature of copper, nickel, and tungsten targets as function of energy deposition. 


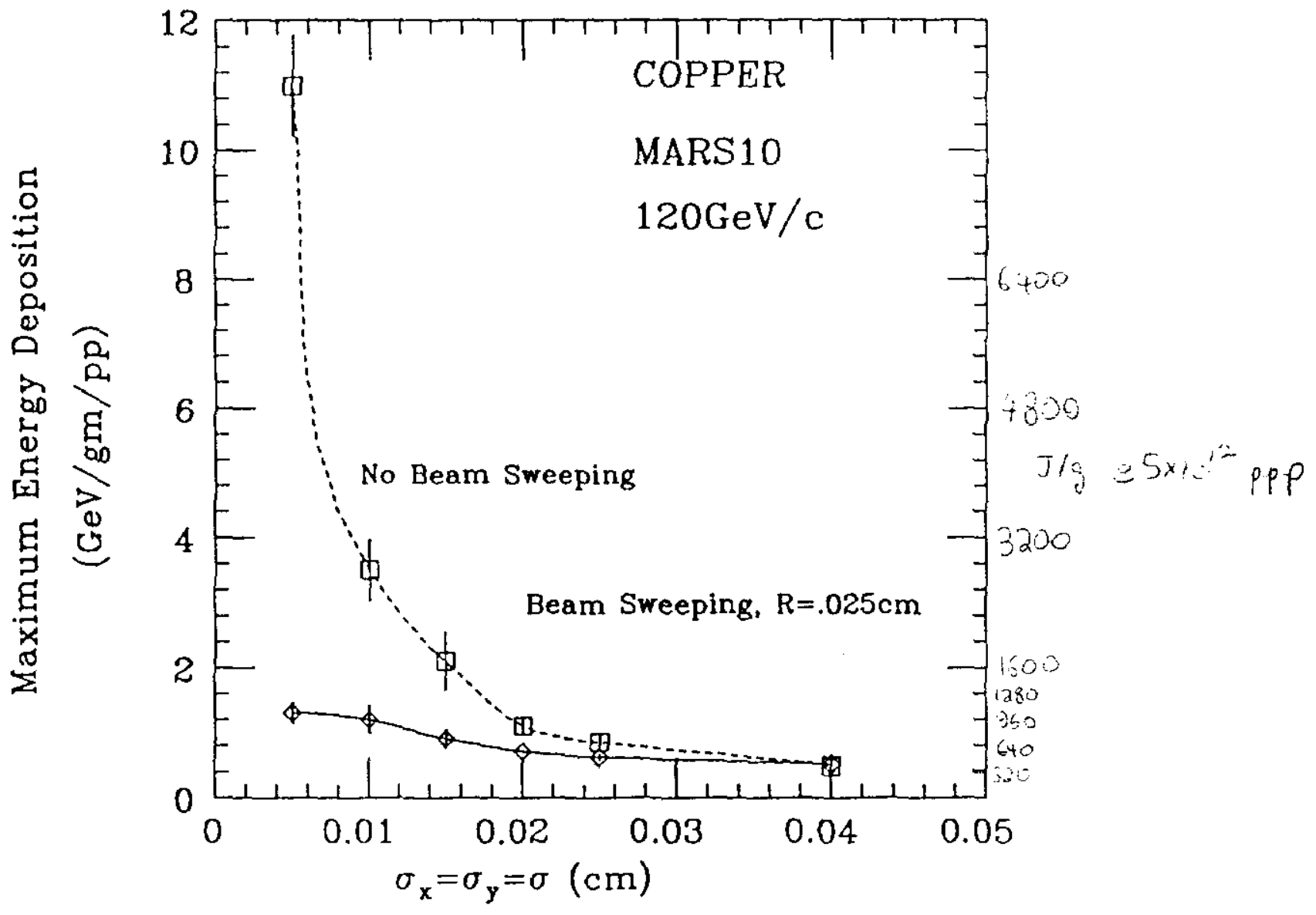

Fig. 4 Maximum energy deposition versus average beam spot size for beam sweeping $(R=0.025 \mathrm{~cm})$ and no beam sweeping. Curves are drawn to guide the eye. Vertical bars represent statistical errors. 


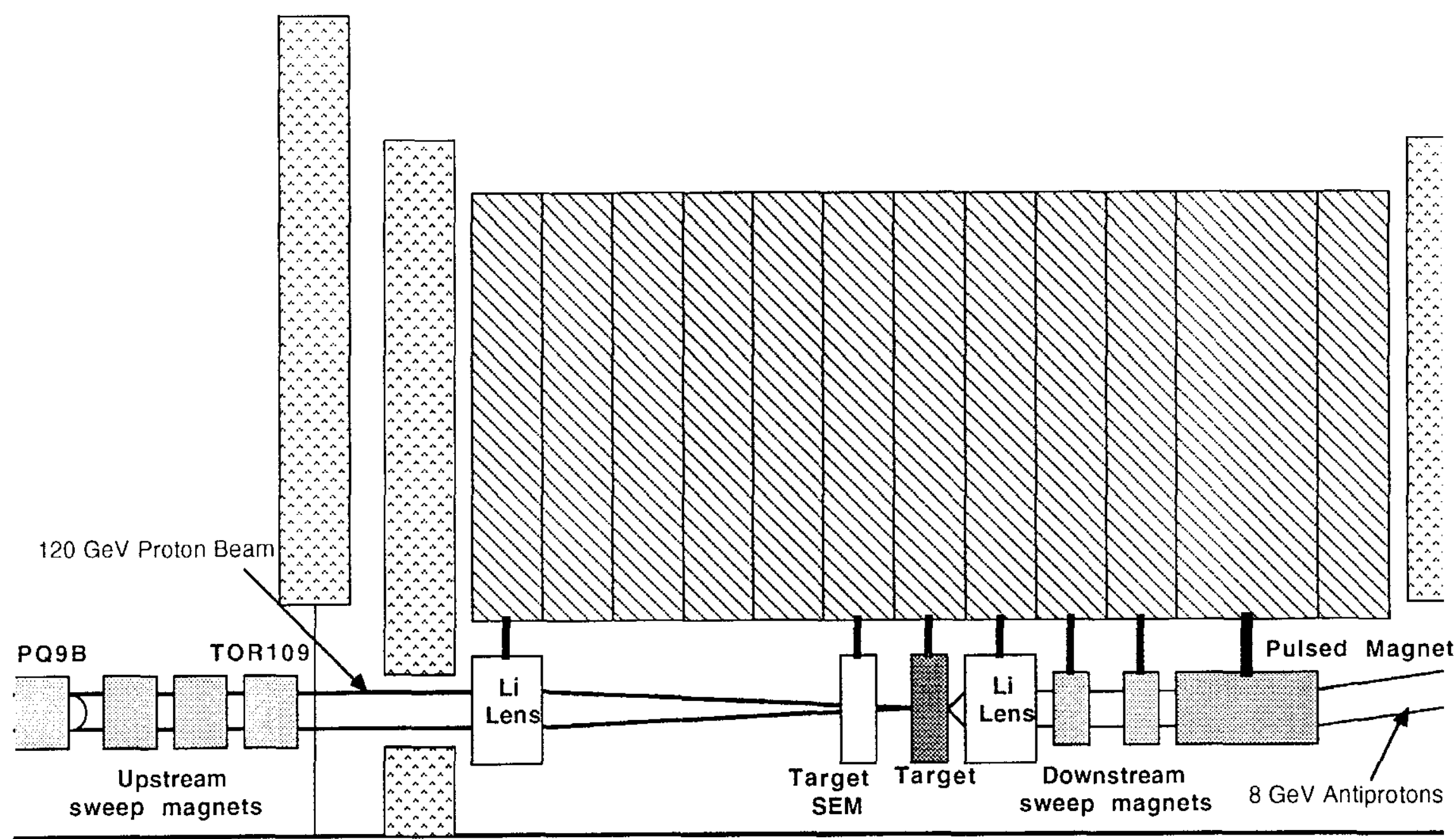

Fig. 5. Layout of target vault, with locations of sweep magnets shown. 


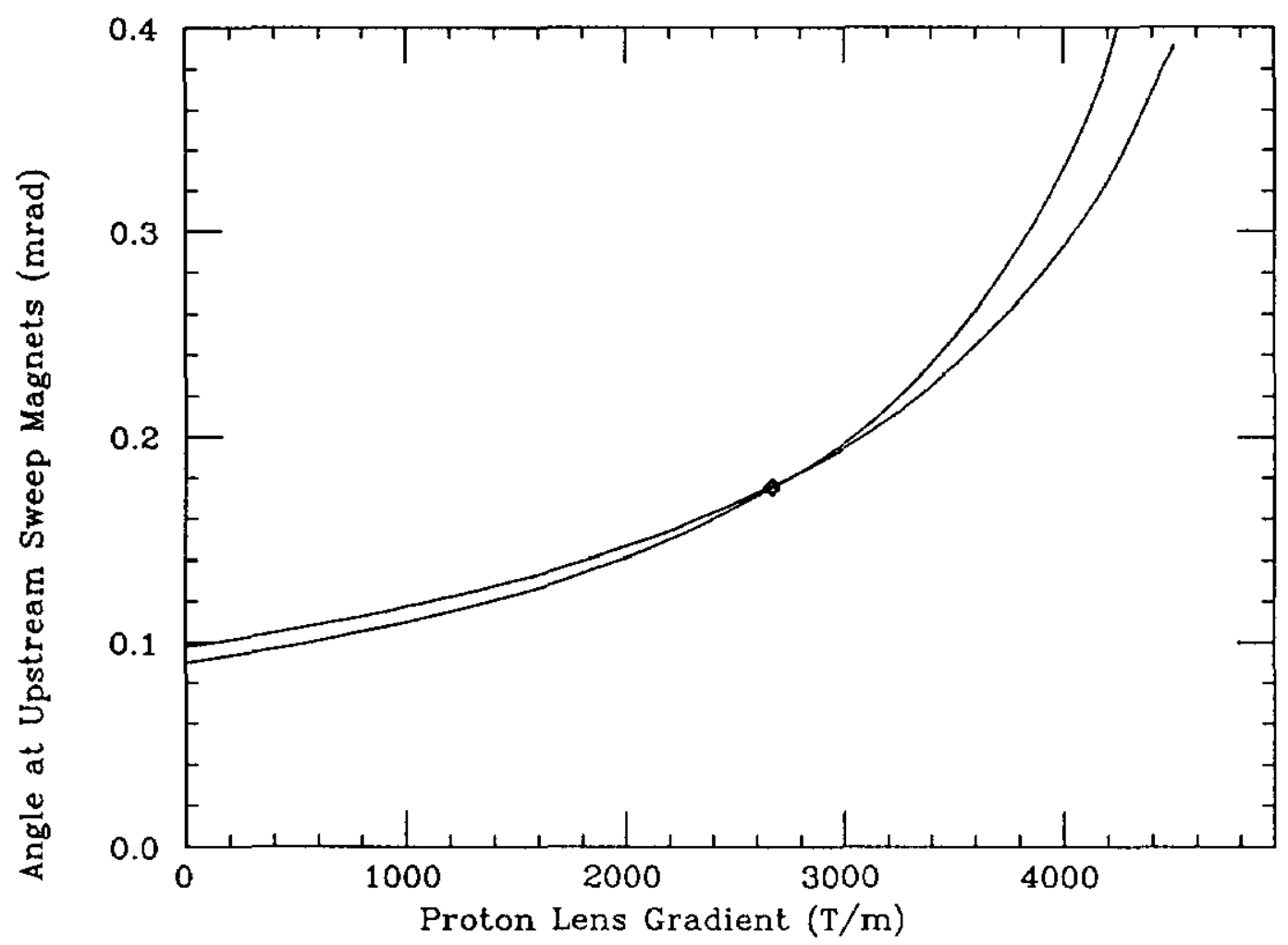

Fig.6. Dependence of upstream deflection angle on proton lens strength. 


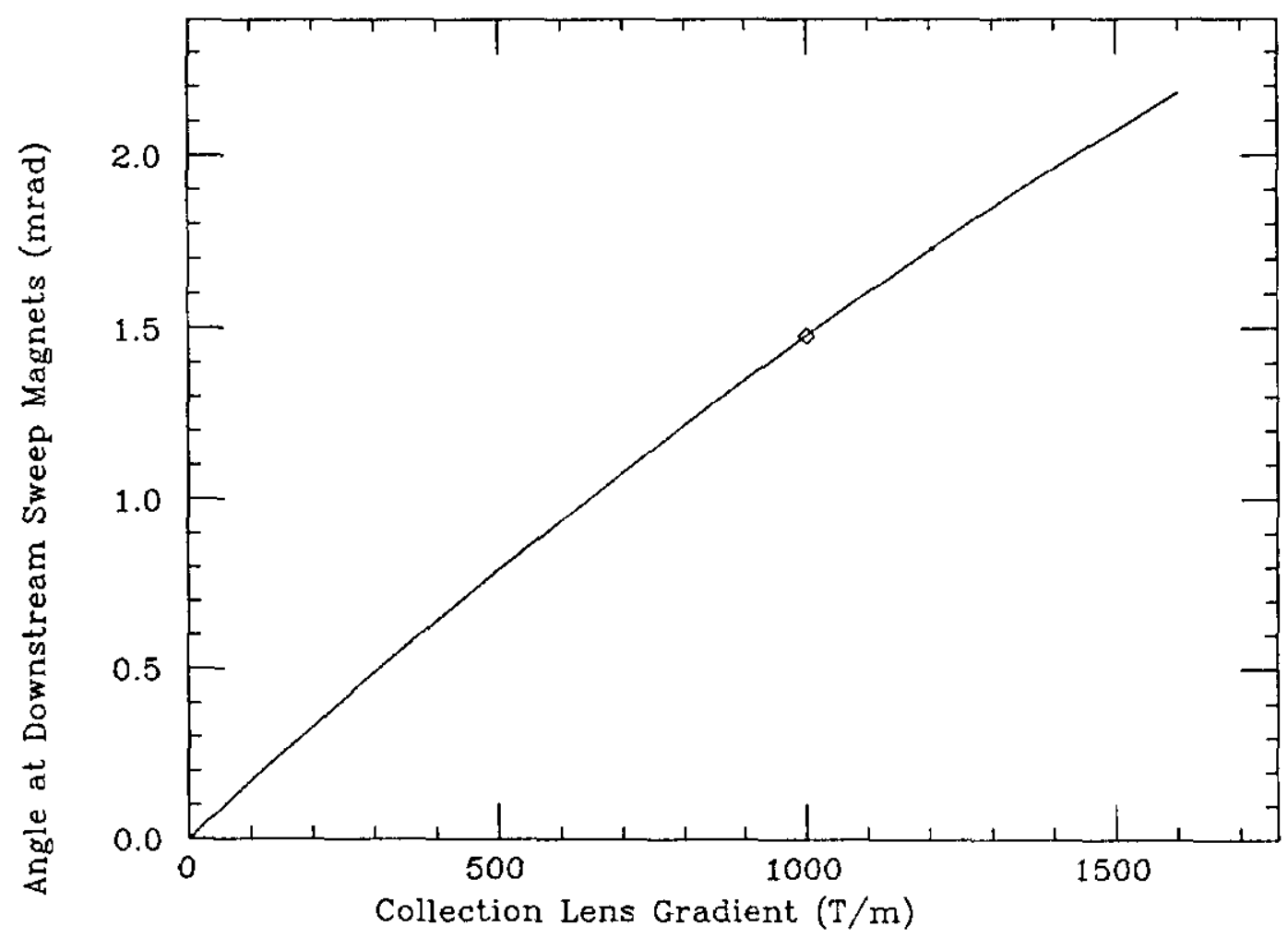

Fig.7. Dependence of downstream deflection angle on collection lens strength. 


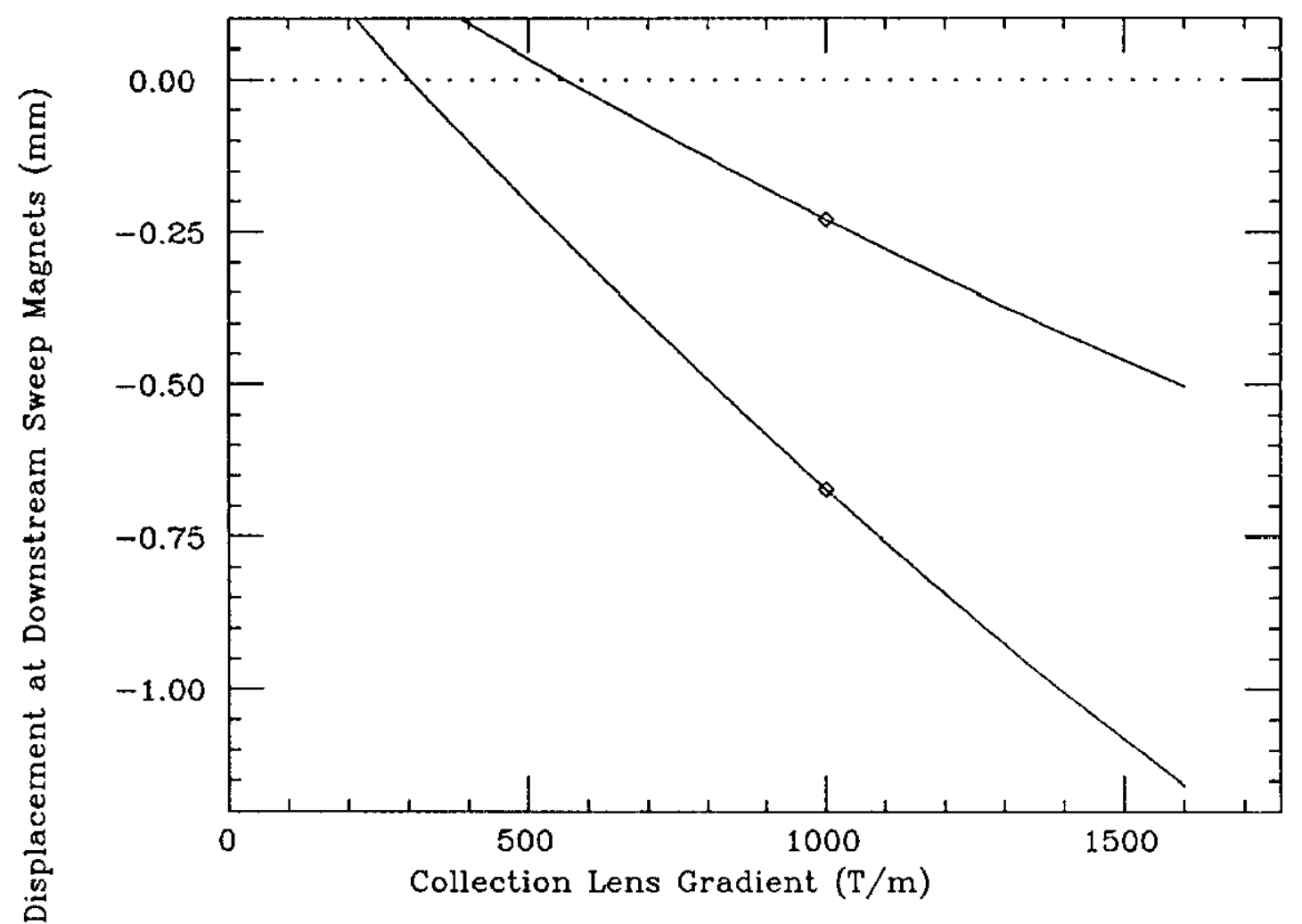

Fig.8. Dependence of downstream displacements on collection lens strength. 


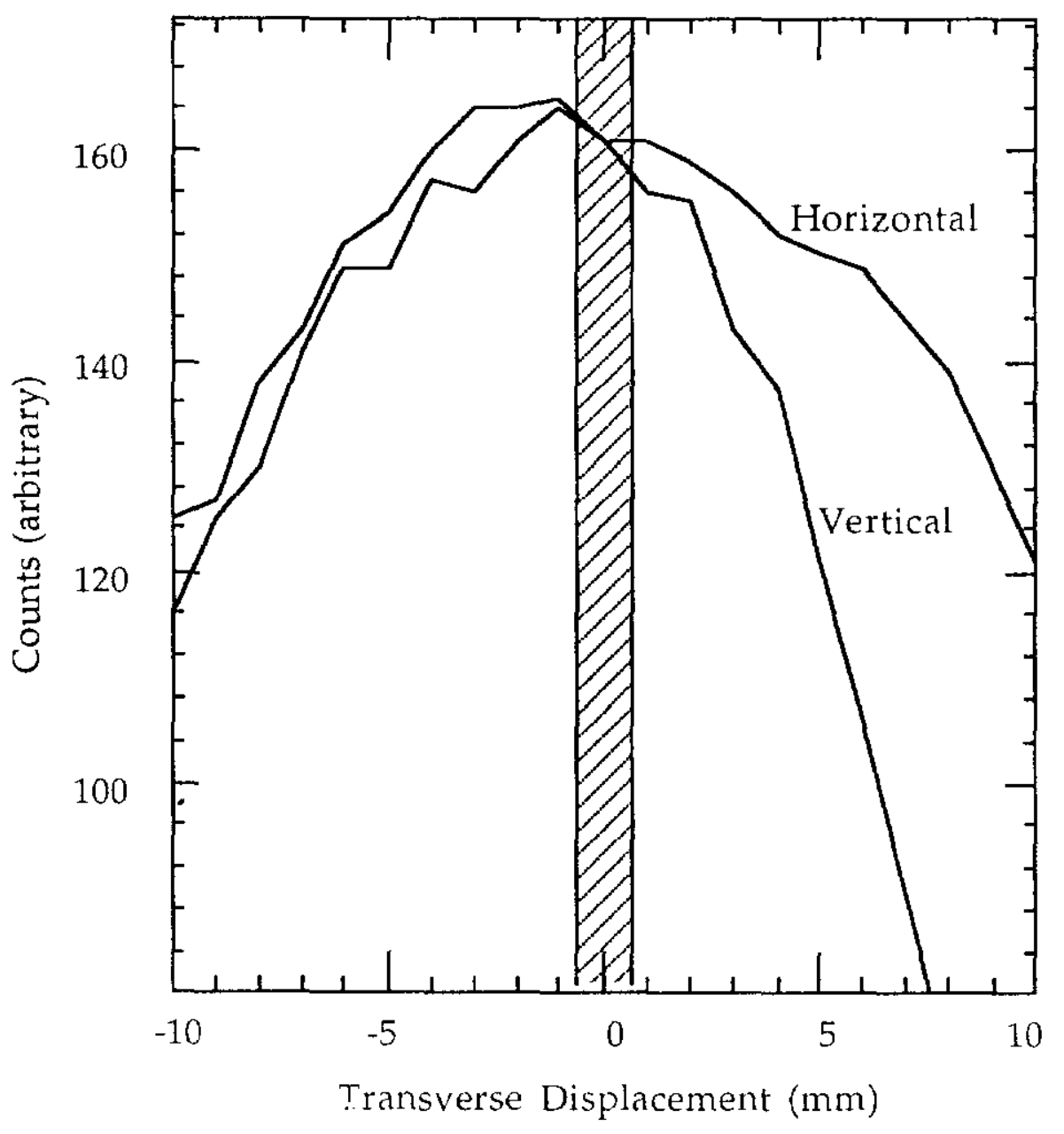

Fig. 9. AP2 acceptance with a displaced input (TURTLE).

Hatched region indicates displacement due to sweep system. 


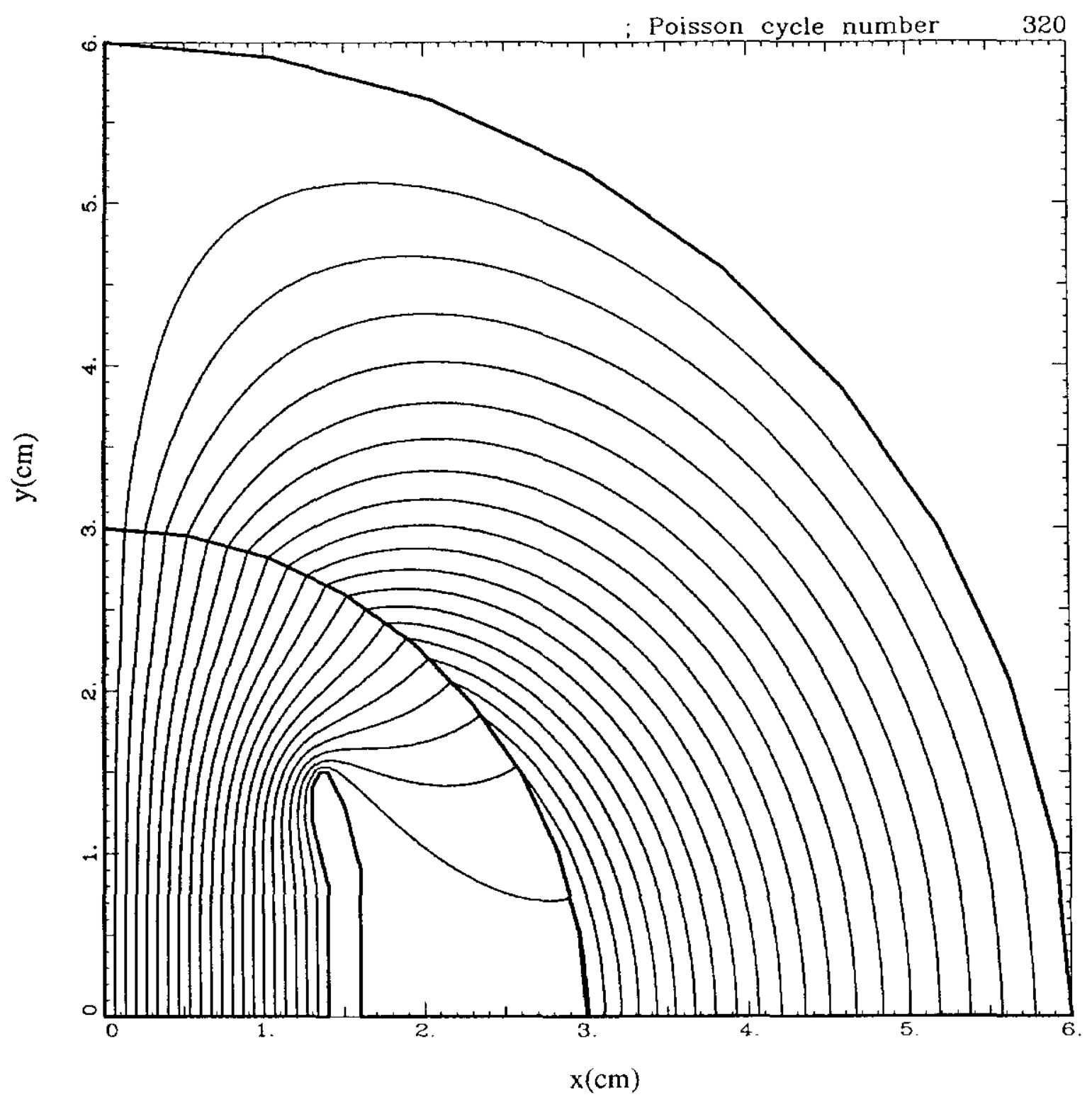

Figure 10. Cross-sectional view of $1 / 4$ of downstream sweep magnet, showing magnetic equipotential lines. 


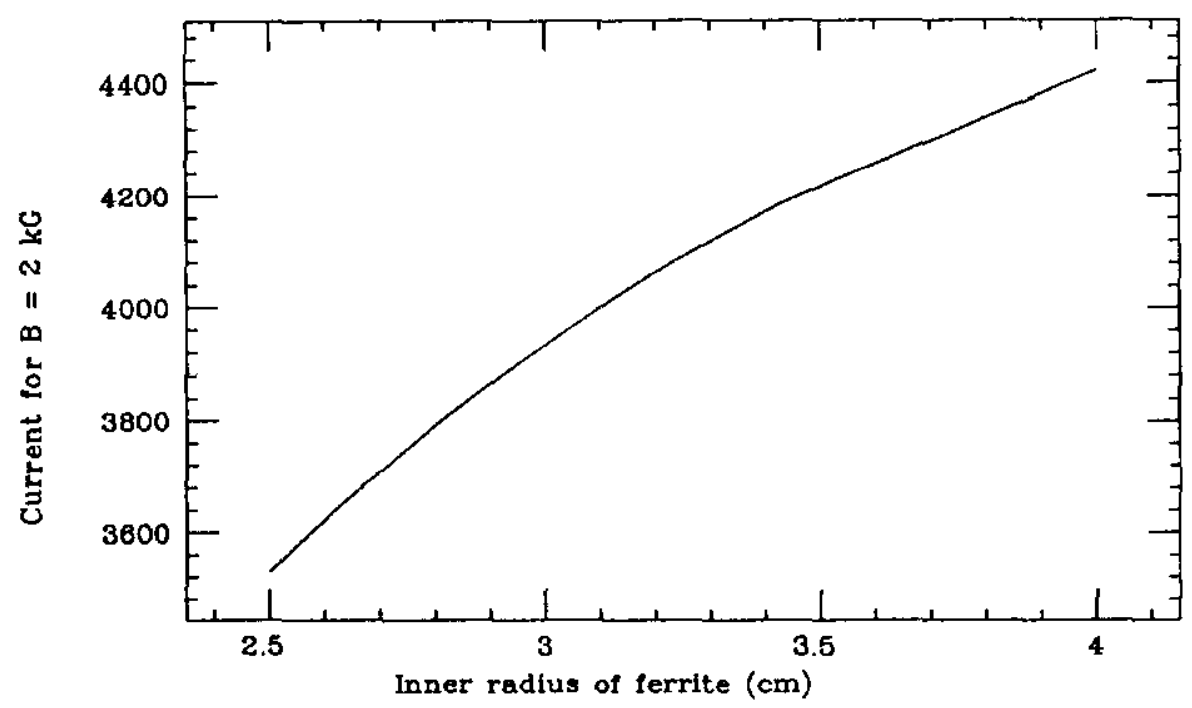

Fig. 11. Downstream sweep magnet, $m u=1000$.

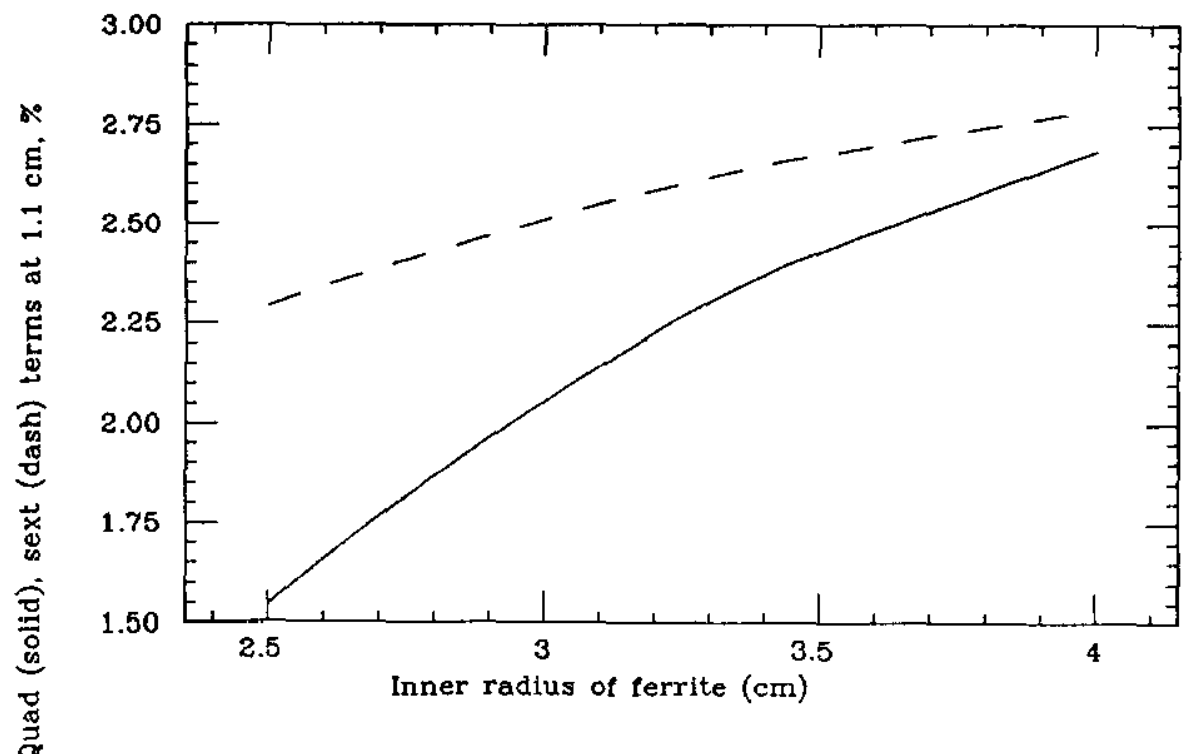

Fig. 12. Downstream sweep magnet, $\mathrm{mu}=1000$. 


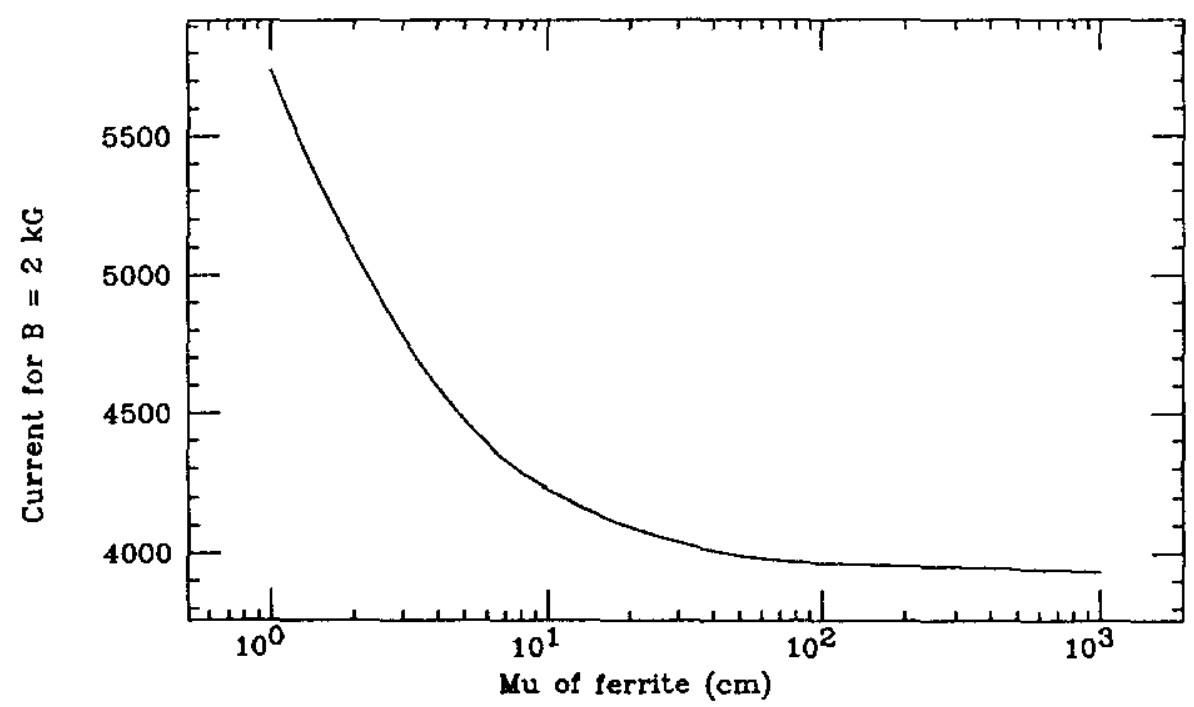

Fig. 13. Downstream sweep magnet, ferrite radius $=3 \mathrm{~cm}$.

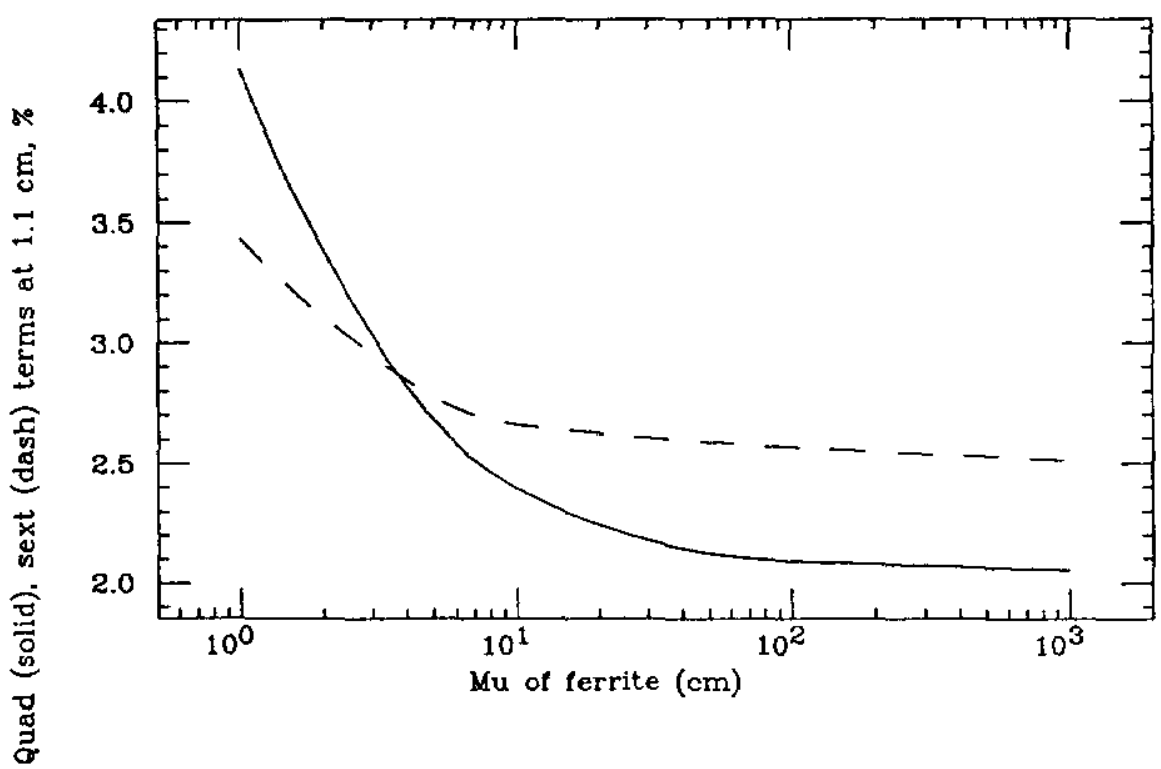

Fig. 14. Downstream sweep magnet, ferrite radius $=3 \mathrm{~cm}$. 


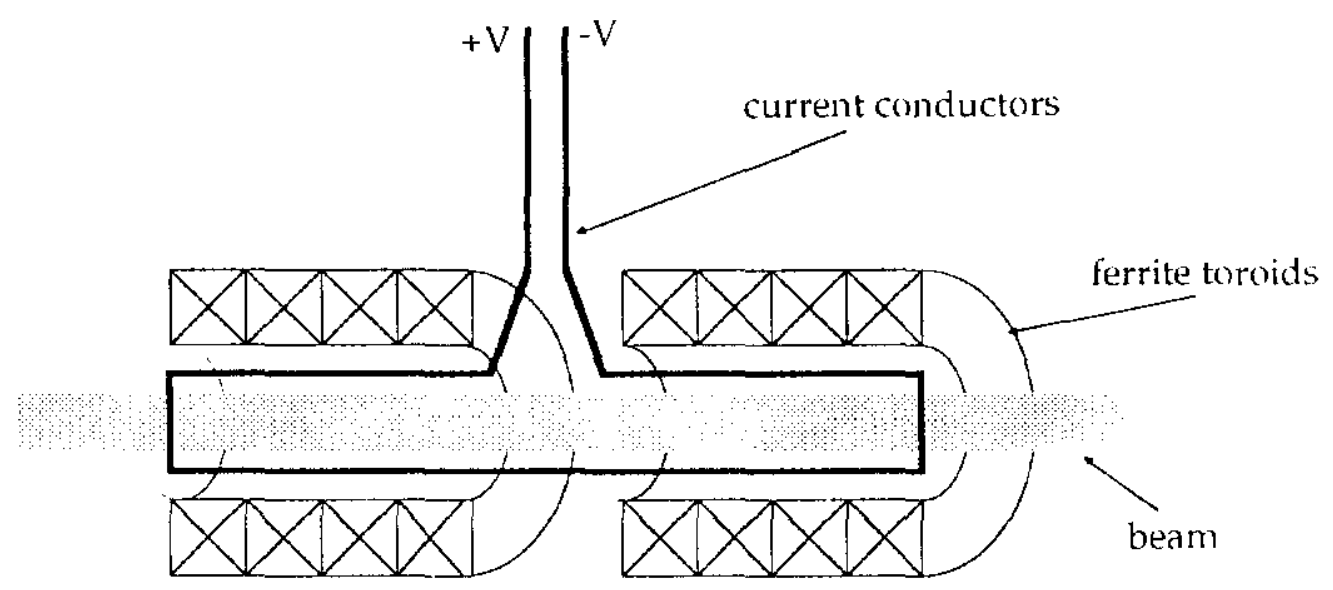

(a)

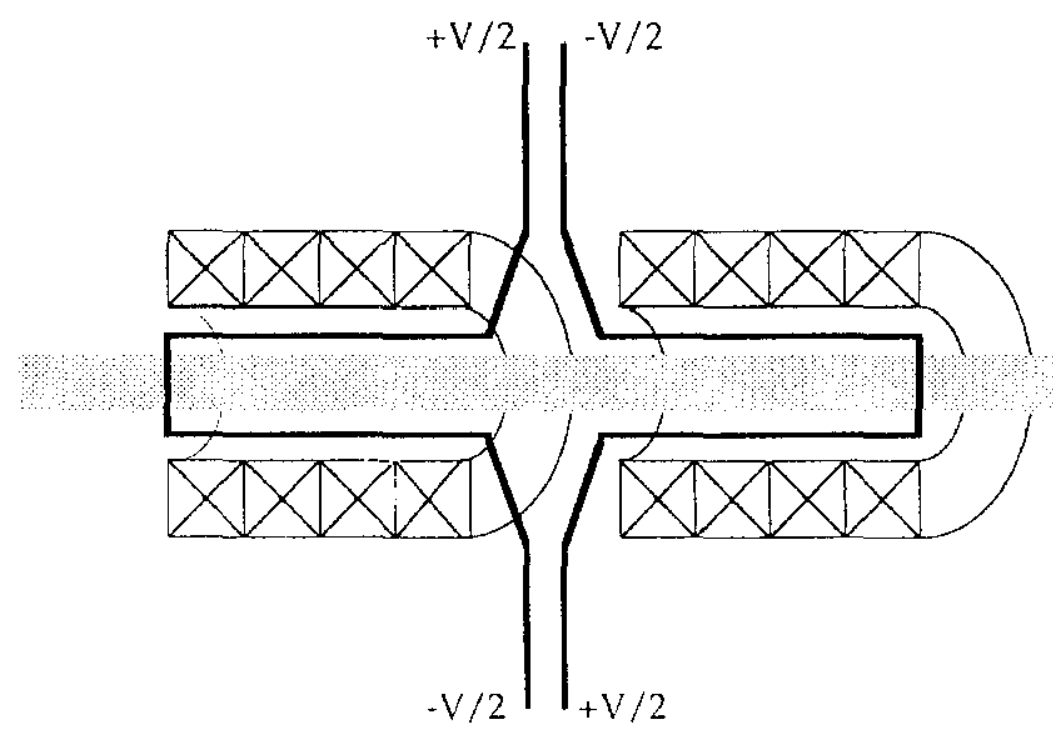

(b)

Fig. 16. Sides view of downstream sweep magnet: (a) center-fed, (b) balanced center-fed. 


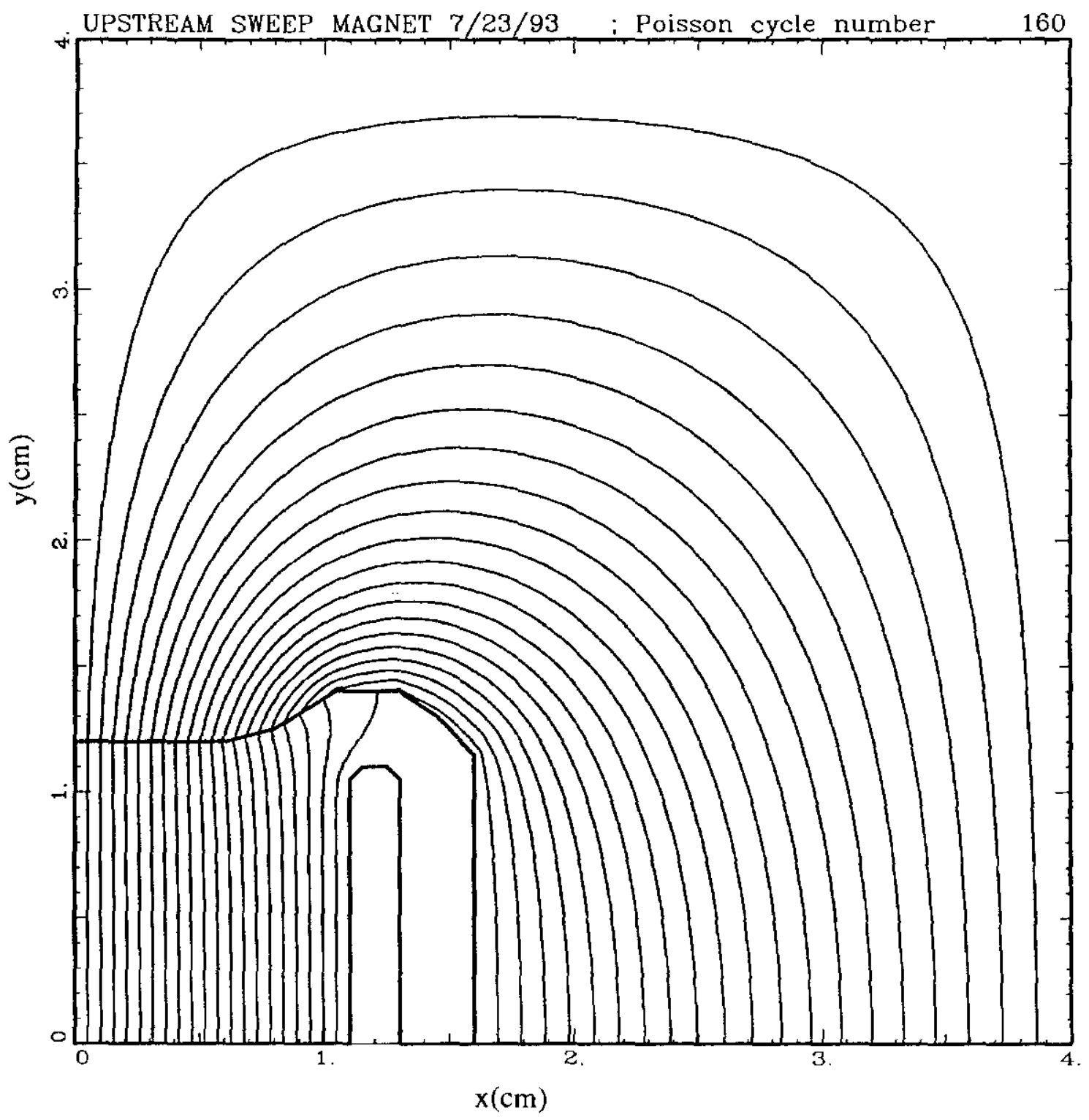

Figure 17. Cross sectional view of $1 / 4$ of upstream sweep magnet, showing magnetic equipotential lines. 


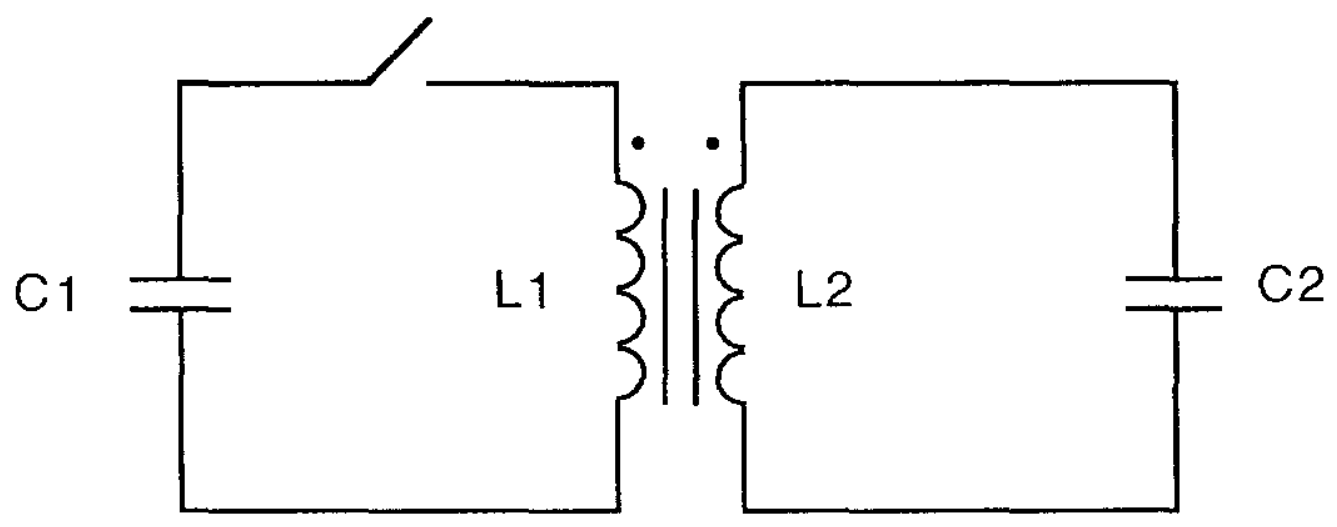

(a)

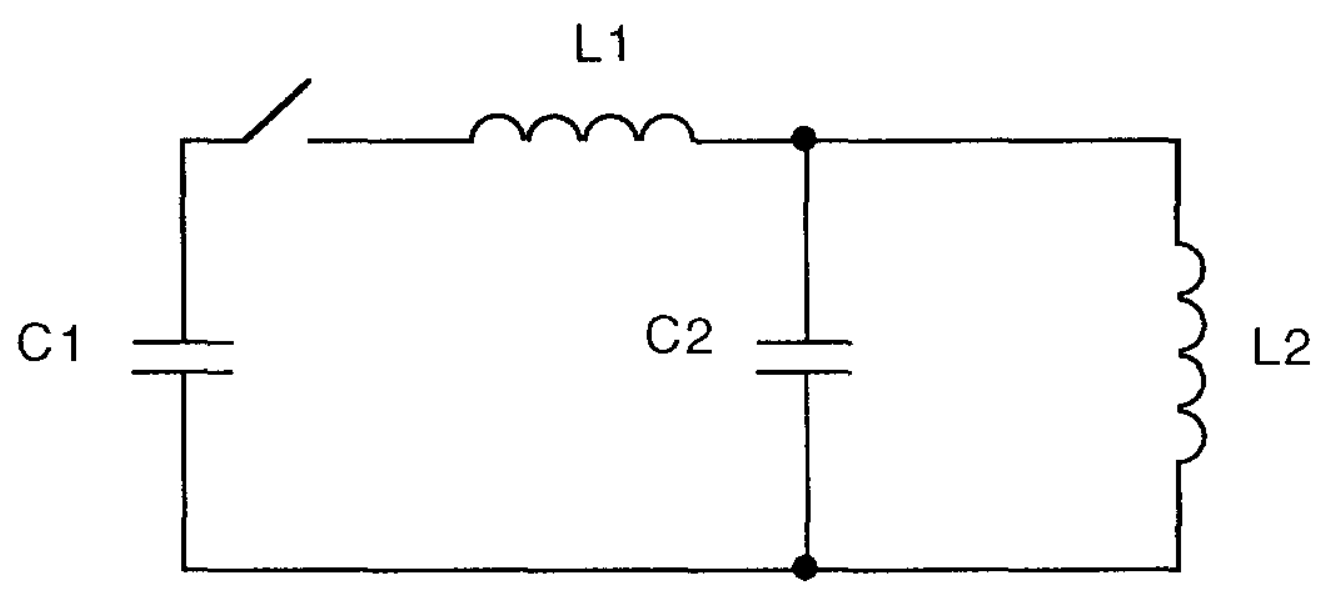

(b)

Figure 18. Coupled resonant circuits: (a) transformer coupled, (b) directly coupled. 


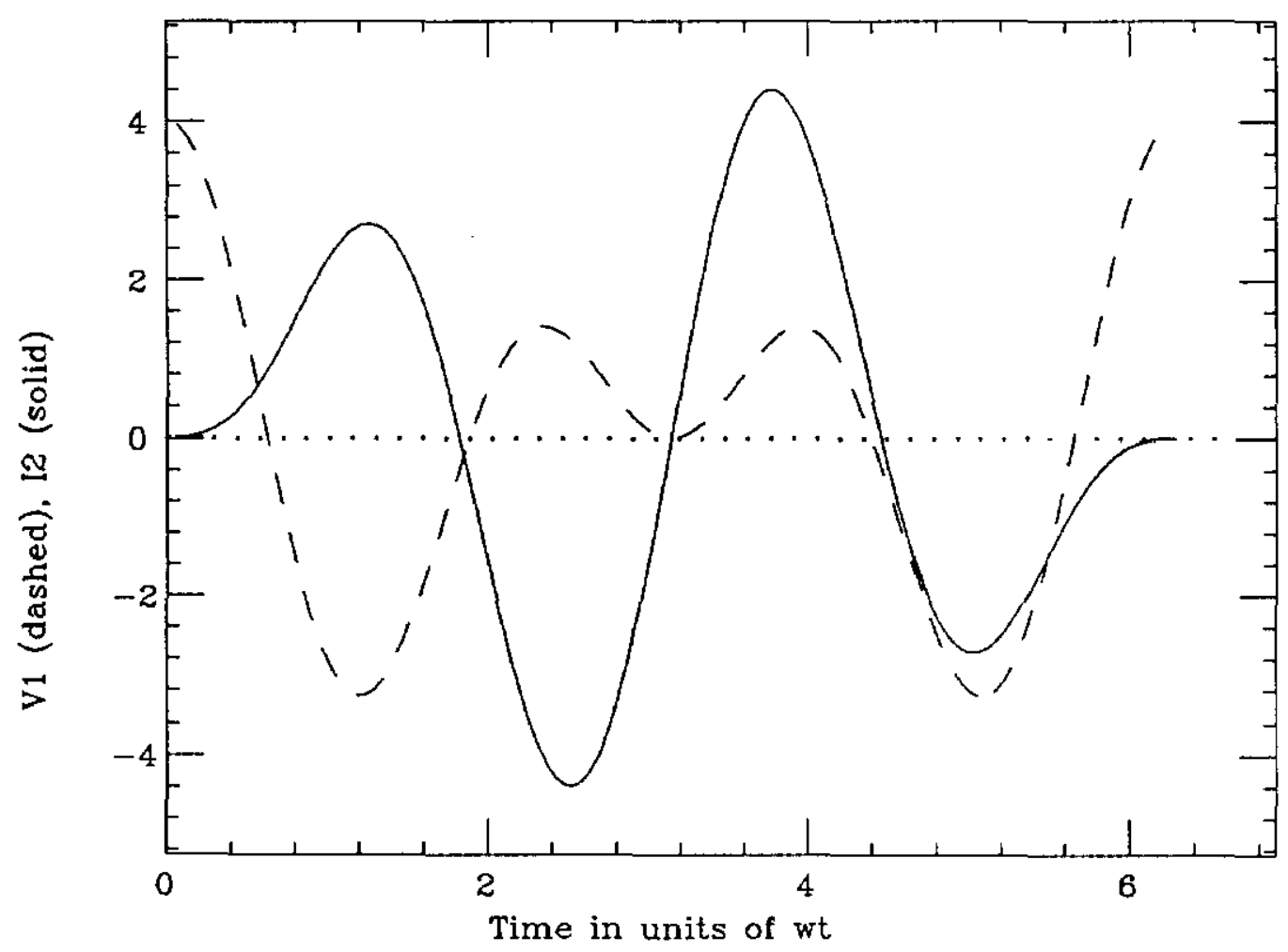

Figure 19. Voltage and current waveforms in an idealized $n=2, m=3$ circuit. 


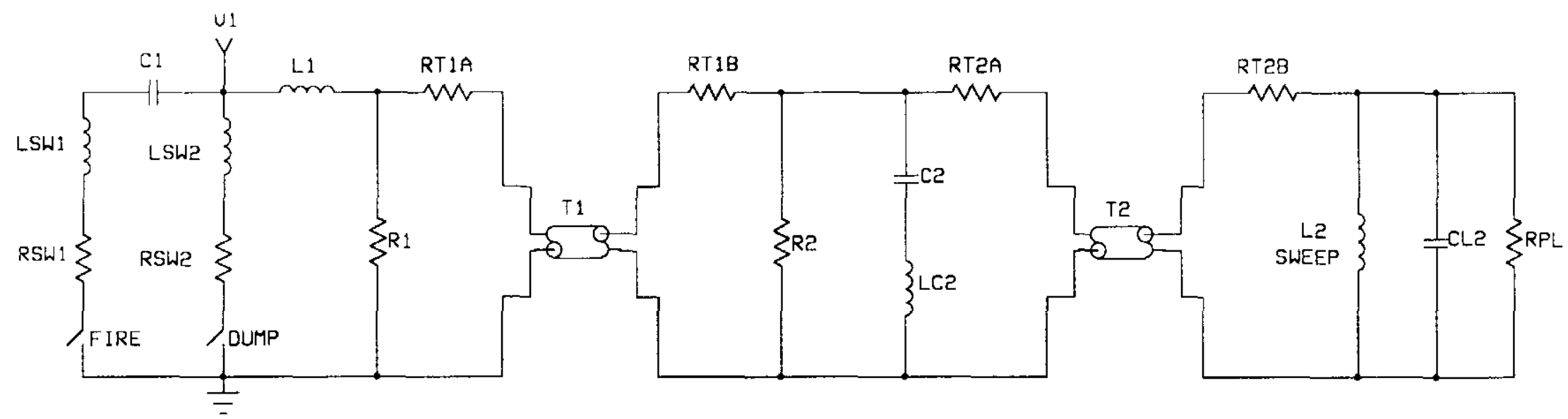

Figure 20. Circuit used for SPICE model of the sweeping system. Components are defined in Table 2. 


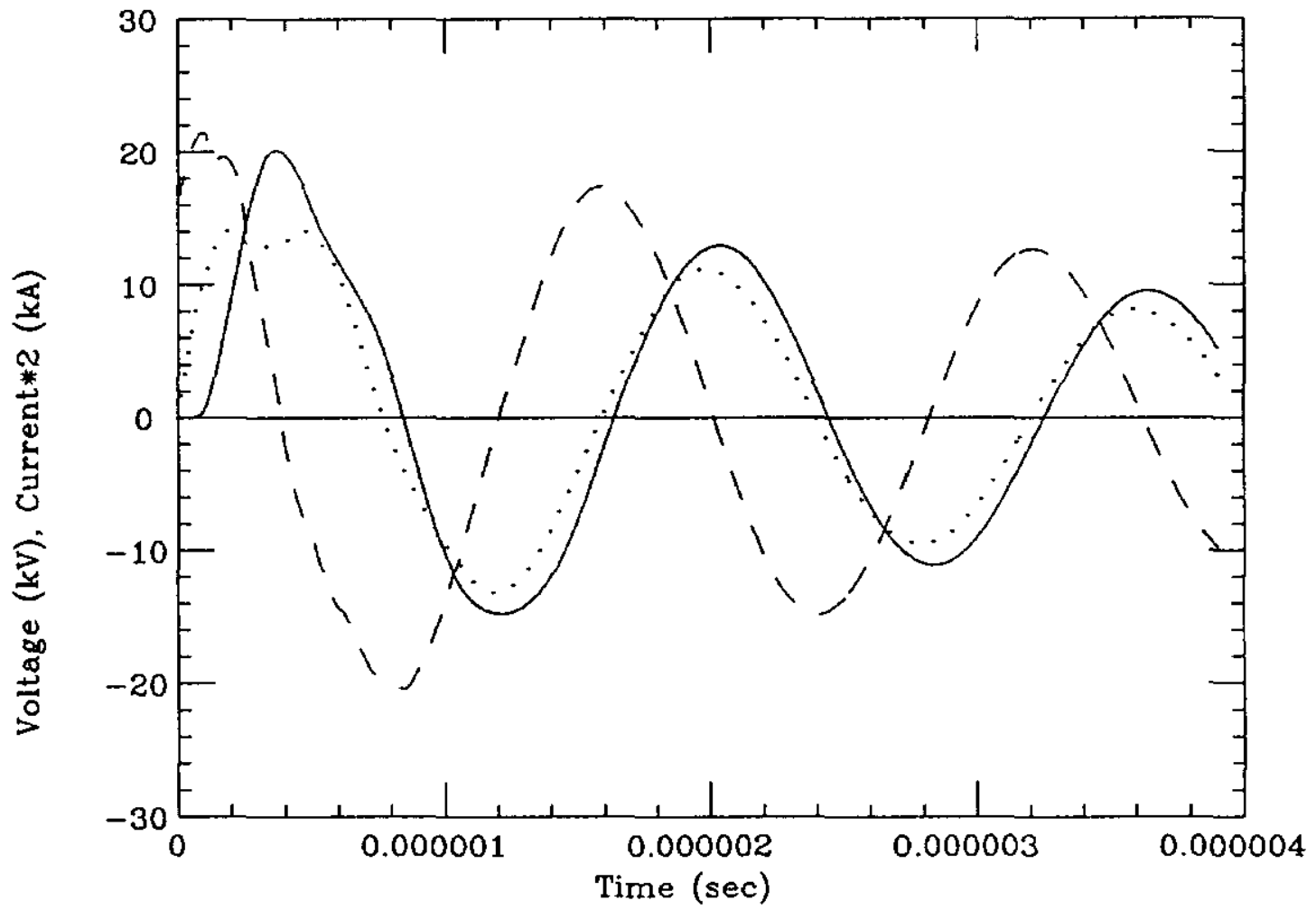

Figure 21. Series circuit (downstream), $32 \mathrm{kV}$ initial charge on $\mathrm{C} 1$ : V1 dashed, 2*I(fire) dotted, $2 * I$ (sweep) solid. 


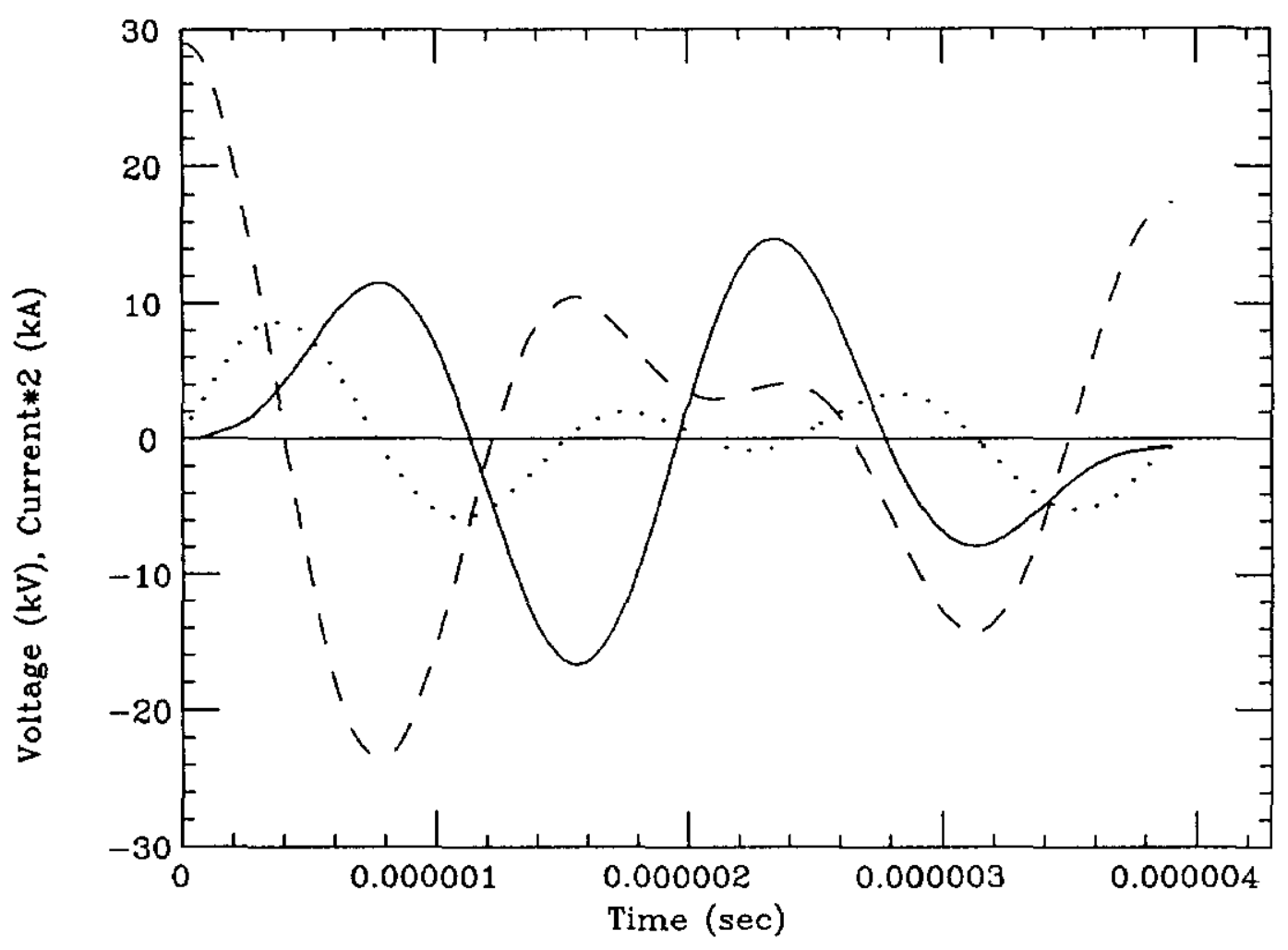

Figure 22. Tuned circuit (downstream), $33 \mathrm{kV}$ initial charge on $\mathrm{C} 1$ : V1 dashed, 2*I(fire) dotted, 2*I(sweep) solid. 


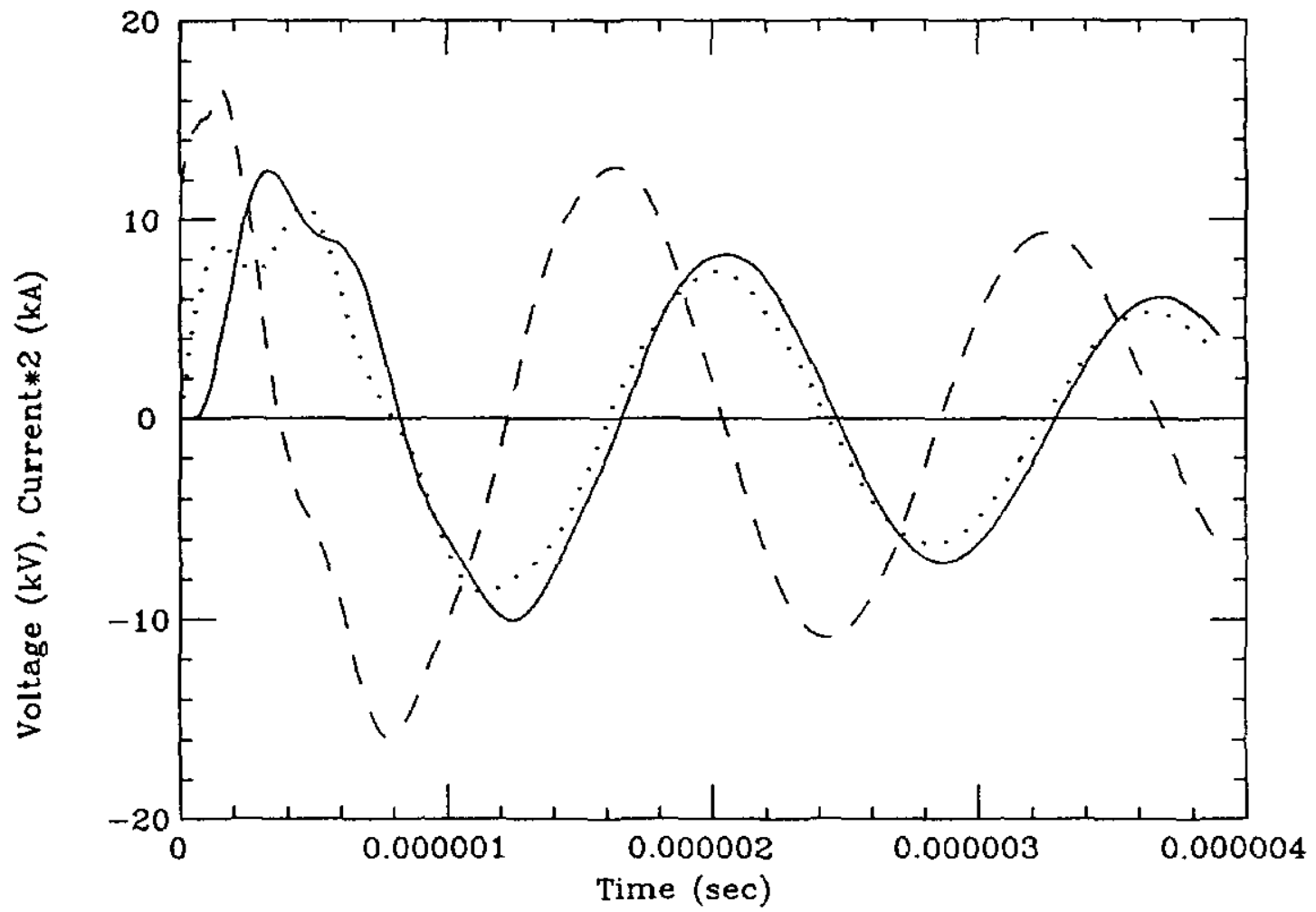

Figure 23. Series circuit (upstream), $23 \mathrm{kV}$ initial charge on C1:

V1 dashed, 2*I(fire) dotted, 2*I(sweep) solid. 


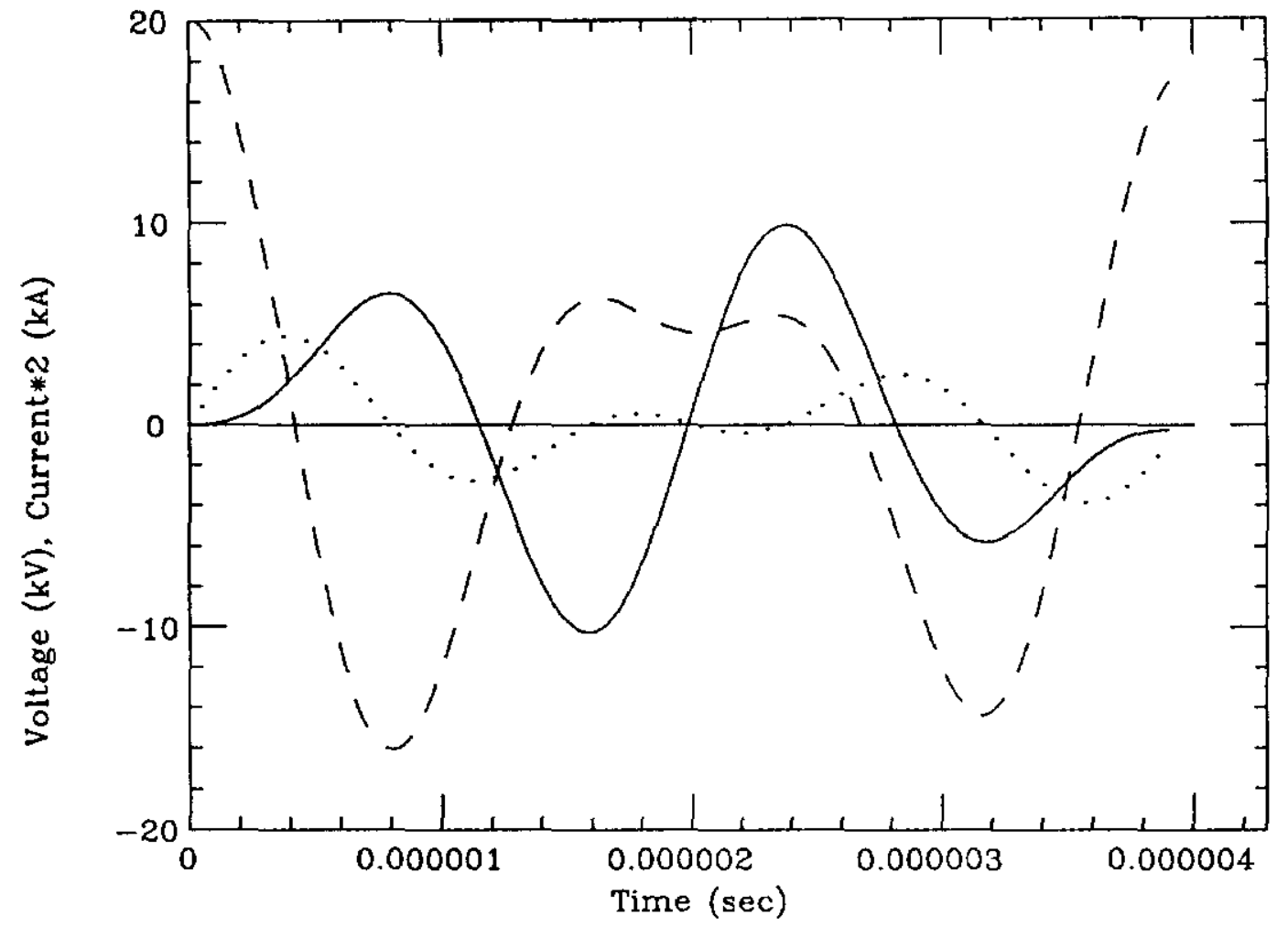

Figure 24. Tuned circuit (upstream), $22 \mathrm{kV}$ initial charge on $\mathrm{C} 1$ : V1 dashed, 2*I(fire) dotted, 2*I(sweep) solid. 


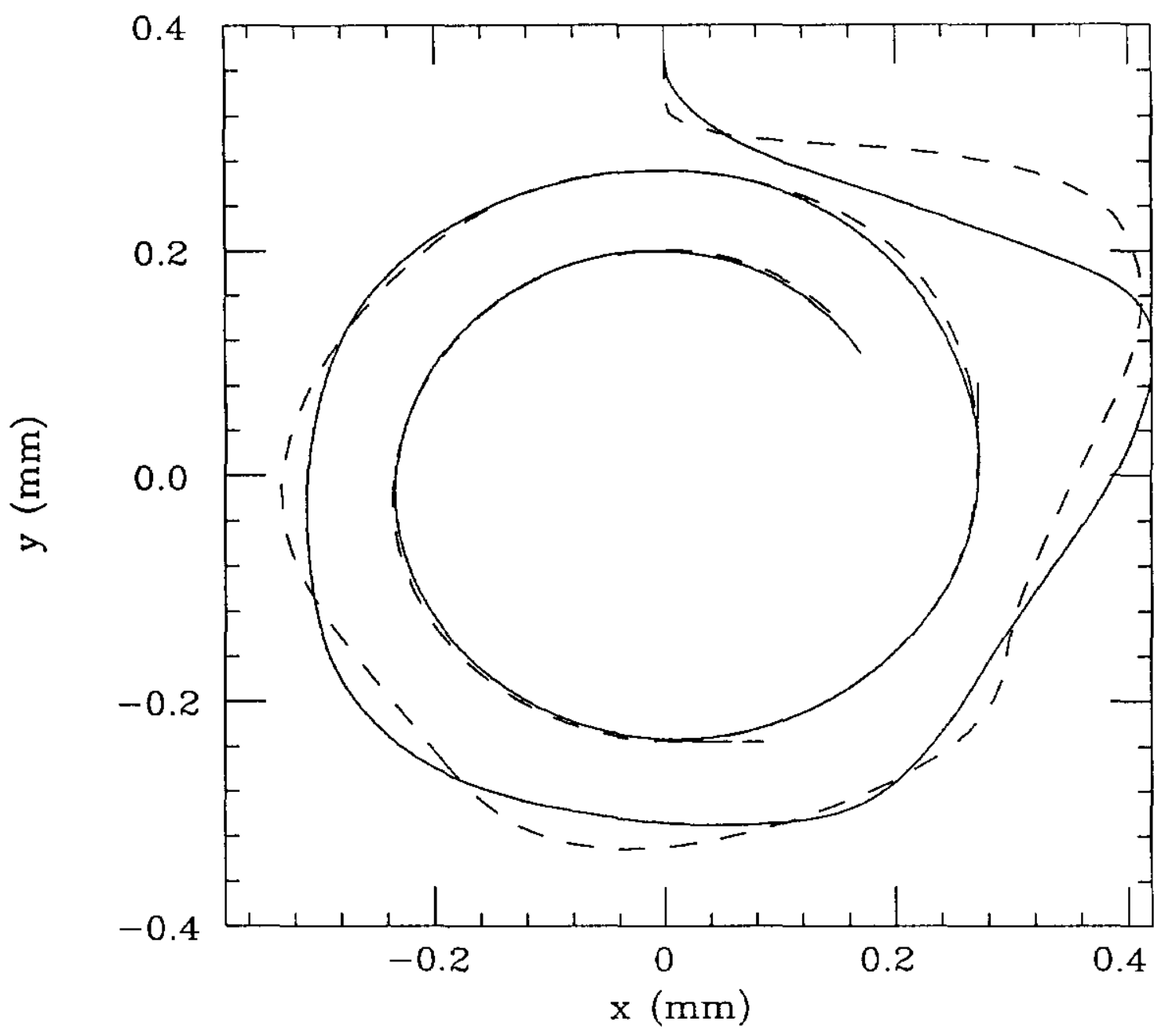

Figure 25. Pattern traced out on the target with the series circuit: upstream (dashed), downstream (solid). 


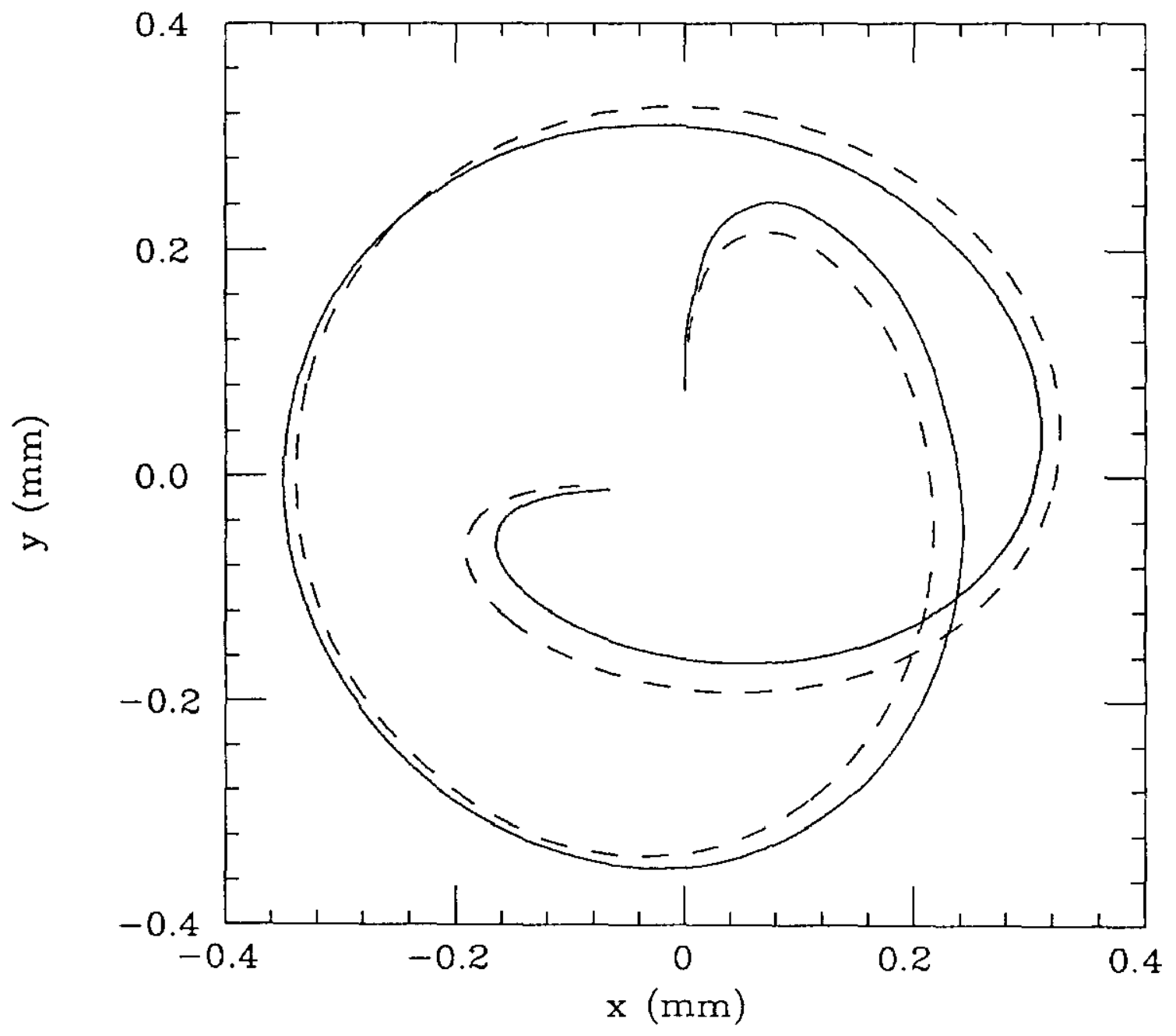

Figure 26. Pattern traced out on the target with the tuned circuit: upstream (dashed), downstream (solid). 


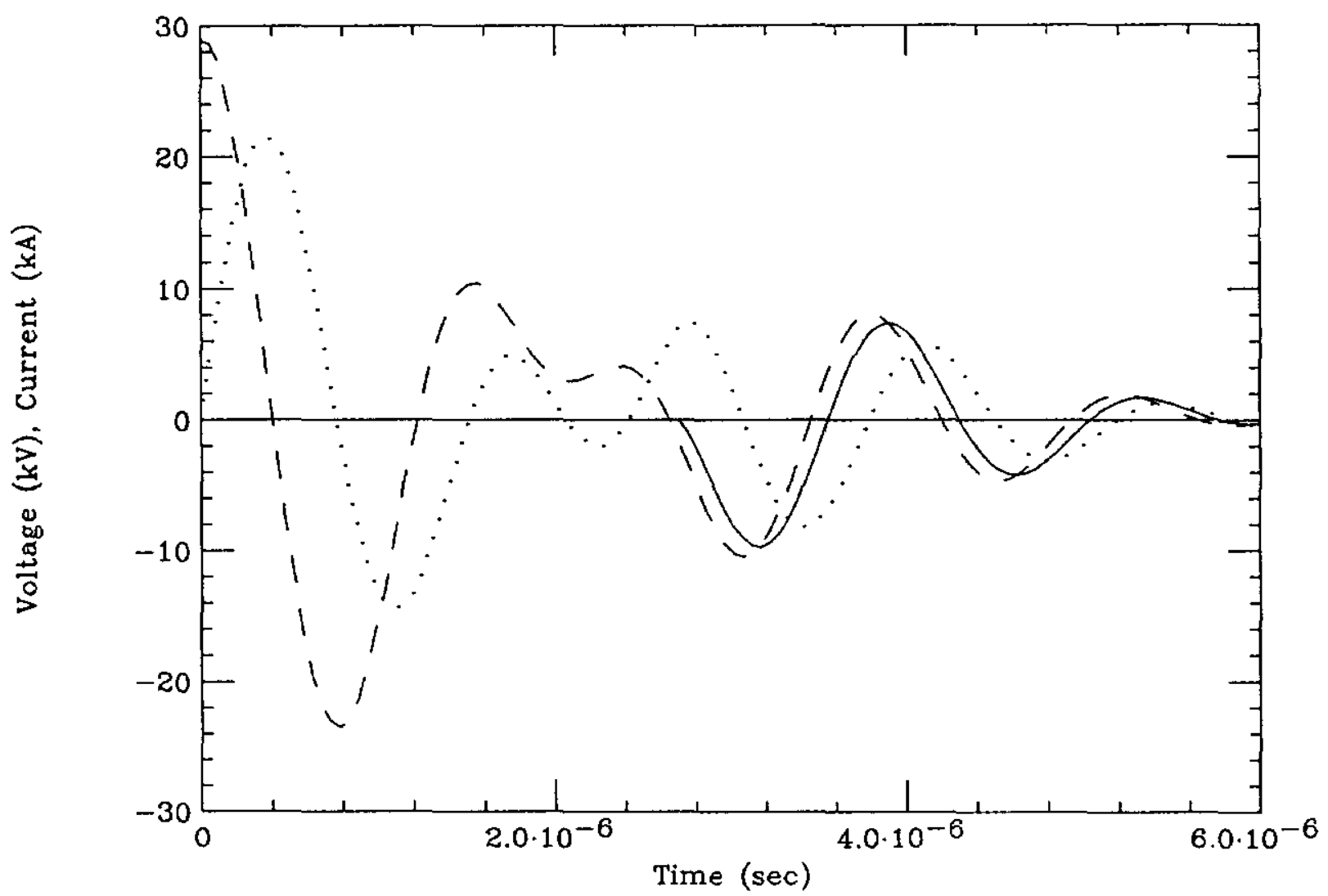

Figure 27. Downstream tuned circuit, dump circuit switched on at 2.8 us: V1 dashed, 5*I(fire) dotted, 10*I(dump) solid. 